\title{
Article \\ Supported-Metal Catalysts in Upgrading Lignin to Aromatics by Oxidative Depolymerization
}

\author{
Cédric Cabral Almada ${ }^{1}$, Aleksandr Kazachenko ${ }^{1,2}$, Pascal Fongarland ${ }^{1,3}$ (D), Denilson Da Silva Perez ${ }^{4}$, \\ Boris N. Kuznetsov ${ }^{2,5}$ and Laurent Djakovitch $1, * \mathbb{D}$
}

1 Institut de Recherches sur la Catalyse et l'Environnement de Lyon (IRCELYON), Université de Lyon, CNRS, IRCELYON, UMR 5256, 2 avenue Albert Einstein, F-69626 Villeurbanne CEDEX, France; cedric.cabral-almada@ircelyon.univ-lyon1.fr (C.C.A.); leo_lion_leo@mail.ru (A.K.); pfo@lgpc.cpe.fr (P.F.)

2 Institute of Chemistry and Chemical Technology SB RAS, Siberian Federal University, 660041 Krasnoyarsk, Russia; bnk@icct.ru

3 Laboratoire de Génie des Procédés Catalytiques, UMR 5285, CNRS, CPE, Université Claude Bernard Lyon 1, 43, bd du 11 Novembre 1918, B.P. 82077, 69616 Villeurbanne CEDEX, France

4 Institut Technologique FCBA-InTechFibres, Domaine Universitaire, CS 90251, 38044 Grenoble CEDEX 9, France; denilson.dasilvaperez@fcba.fr

5 Institute of Chemistry and Chemical Technology, Siberian Branch, Russian Academy of Sciences, 660036 Krasnoyarsk, Russia

* Correspondence: laurent.djakovitch@ircelyon.univ-lyon1.fr

check for updates

Citation: Cabral Almada, C.; Kazachenko, A.; Fongarland, P.; Da Silva Perez, D.; Kuznetsov, B.N.; Djakovitch, L. Supported-Metal Catalysts in Upgrading Lignin to Aromatics by Oxidative

Depolymerization. Catalysts 2021, 11, 467. https://doi.org/10.3390/ catal11040467

Academic Editor: Changzhi Li

Received: 4 March 2021

Accepted: 25 March 2021

Published: 2 April 2021

Publisher's Note: MDPI stays neutral with regard to jurisdictional claims in published maps and institutional affiliations.

Copyright: (C) 2021 by the authors. Licensee MDPI, Basel, Switzerland. This article is an open access article distributed under the terms and conditions of the Creative Commons Attribution (CC BY) license (https:// creativecommons.org/licenses/by/ $4.0 /)$.
Abstract: Supported gold and platinum particles on titanium oxide catalysts were evaluated in the oxidative depolymerization of lignins toward high added value aromatics under mild conditions (T: $150{ }^{\circ} \mathrm{C}, \mathrm{P}_{\text {air }}: 20$ bar, $\mathrm{C}_{\mathrm{NaOH}}: 10 \mathrm{~g} / \mathrm{L}, 1 \mathrm{~h}$ ). Kraft and ethanol Organosolv lignins were engaged in the study. Gold catalyst showed a strong tendency to further oxidize aromatics produced from lignin depolymerization to volatile compounds leading to very low yield in target molecules. On the contrary, platinum-based catalysts were allowed to observe enhanced yields that were attributed to its ability to preserve lignin's substructure during the reaction. A kinetic model was constructed based on the results observed, which allowed us to identify the occurrence of condensation reactions during lignin oxidation and degradation of the produced aromatic compounds as the main limitations to reach high product yields. Insights on lignin oxidation and the catalyst's role lead through this study would help to reach higher control over lignin valorization.

Keywords: catalytic lignin depolymerization; aromatics; organosolv lignin; kraft lignin; oxidative conditions; kinetic model

\section{Introduction}

Lignin, one of the main biopolymers from lignocellulosic biomass, appears to be a promising feedstock for producing sustainable aromatic chemicals. Despite its high availability, its upgrading to added-value molecules remains under-developed due to numerous hindrances caused by the structure of the material and its derivatives as well as their analysis. However, lignin's high potential has led to thorough research in this area. Several approaches have been reported and reviewed [1-10], which often use molecular models to mimic lignin fragments to understand the reaction mechanisms and the role of the catalysts. However, when applied to lignin, studies suffered from limitation as the models could not mimic the all biopolymers [11,12].

In this contribution, we focus mainly on the oxidative upgrading of lignin in aqueous media to produce functional aromatic compounds such as aromatic aldehydes or ketones. Studies on catalyst-free oxidation of lignin have commonly reported yields of vanillin, one of the main products, between $1 \mathrm{wt} \%$ to $6.8 \mathrm{wt} \%$ in accordance with their botanical and extraction process, thus showing the importance of the choice of the starting material in 
the process [2,3,13-15]. Recently, Schutyser et al. reported yields of $\sim 30 \mathrm{wt} \%$ yields of aromatics (vanillin: $7 \mathrm{wt} \%$ ) using native lignin, i.e., poplar sawdust [15].

To obtain higher yields of aromatics from lignin oxidation, a wide variety of catalysts have been evaluated with homogeneous catalysis (i.e., bioinspired, organometallic and metallic salts catalysts) being the most evaluated approach, often due to its implication in bleaching processes [16-18].

Based on methodologies used by microorganisms capable of degrading lignin, several biomimetic catalysts have been developed $[1,11,19,20]$ such as the metal-porphyrin (iron, manganese) complexes reported by Crestini et al. [21,22] or the metallo-deuteroporphyrin, derived from hemin in the presence of oxone evaluated by Zhu et al. more recently [23]. Lignin treated by these compounds usually presents extensive modification, i.e., cleavage of inter-unit bonds and a higher concentration of carbonyl functions; however, analysis of low molecular was not commonly considered. Organometallic compounds have also been considered as catalysts for lignin upgrading. Crestini et al. first reported the evaluation of MethylTrioxoRhenium (MTO) for lignin depolymerization with results similar to those obtained with metal-porphyrin mentioned earlier [16]. Recently, Kühn, Cokoja and co-workers demonstrated the mechanism of $\mathrm{C}-\mathrm{O}$ bond cleavage when using MTO on lignin model compounds [24]. PolyOxoMetallates (POMs) were also investigated as lignin oxidation catalysts given their involvement in delignification processes [11]. Using different types of lignin, the group of Von Rohr and Gao managed to greatly affect lignin structure (e.g., lower $\mathrm{M}_{\mathrm{W}}$ ) and recover up to $17 \mathrm{wt} \%$ of low molecular weight aromatic compounds [25]. Recently, Rawat et al. described the use of molybdenum pyrophosphate supported on cerium oxide $\left(\mathrm{MoPO} / \mathrm{CeO}_{2}\right)$ for the oxidative lignin depolymerization in basic medium under mild conditions [26]. Lignin oxidative depolymerization has also been assessed in the presence of $\mathrm{Co}$ (Salen) complexes delivering up to $3 \mathrm{wt} \%$ of vanillin by Zhou and co-workers [27]. Various groups have also investigated the influence of metallic salts for lignin's upgrading, with copper, iron, cobalt and manganese being the most studied $[11,12,28]$. They commonly showed great activity in producing aromatic compounds from lignin. Copper salts probably delivered the highest yields as attested by its application in the Borregaard process aiming to produce vanillin from lignosulfonates [29].

Heterogeneous catalysts play a major role in the development of industrial processes due to their numerous advantages. In the case of lignin upgrading, the ability to separate and recover efficiently the reaction products is a great asset given the high number of compounds obtained through oxidation. To benefit from this aspect, many research groups have evaluated the immobilization of the homogeneous system, such as MTO [30], porphyrinbased complexes [22,31,32] or $\mathrm{Co}($ Salen) [27], on various support ranging from inorganic oxides to organic framework or even activated carbon [33,34]. These systems commonly produced results lower or close to those obtained with their homogeneous counterparts.

Perovskites are well established catalysts for catalytic oxidation of hydrocarbons; they were recently used in lignin oxidative depolymerization and were mostly developed by Liu and coworkers [35-37], following the pioneering works of Yang et al. and Royer et al. $[38,39]$ Using enzymatic extracted lignin from steam-exploded cornstalk, authors demonstrated an improvement of lignin conversion and aromatic compound production with these catalysts; they also showed that the best results were obtained with coppercontaining catalysts such as $\mathrm{LaFe}_{0.8} \mathrm{Cu}_{0.2} \mathrm{O}_{3}$ with $10.8 \%$ and $4.6 \%$ yields of syringaldehyde and vanillin respectively.

Metal oxides are common oxidation catalysts used in oxidative depolymerization of lignin, with $\mathrm{CuO}$, rhenium oxides and associated MTO being probably the most documented $[30,40,41]$. While good activity could be reached, generally the selectivity is not very high, particularly toward vanillin. Recently, Zhu and co-workers reported the use of $\mathrm{ReO}_{x}$ supported on $\gamma-\mathrm{Al}_{2} \mathrm{O}_{3}$ as an efficient catalyst to produce vanillin from Kraft lignin in melted phenol as solvent [42]. Unlike copper salts, $\mathrm{CuO}$ demonstrated mixed results depending on the reports. Indeed, Pearl et al. recovered very low yields in aldehydes [43] while other studies displayed better results $[15,40]$. Kumar et al. reported the use of a 
$\mathrm{Cu}-\mathrm{Mn} / \gamma-\mathrm{Al}_{2} \mathrm{O}_{3}$ in water and ethanol-water co-solvent mixture for the oxidative conversion of prot lignin to phenolic compounds [44]. Barakat and co-workers described the application of $\mathrm{FeCoO}$ mixed-oxide, prepared by nano-nucleation using alginate template, in the oxidative depolymerization of lignin [45], which delivered up to $20 \mathrm{wt} \%$ aromatic molecules with a Fe:Co ratio of 1:1.

Supported noble metal catalysts have been extensively studied for aerobic oxidation of many compounds; therefore, they have also been evaluated for lignin oxidative depolymerization. Cai and co-workers reported the use of cobalt nanoparticles in N-doped porous carbon as catalyst, and they demonstrated a great ability to degrade lignin's inter-units [46]. Authors were able to recover $15 \mathrm{wt} \%$ of aromatic compounds using Organosolv birch lignin in mild conditions. Recently, AuNPs/Li-AL LDH (layered double hydroxide) were evaluated for the depolymerization of Indulin AT Kraft lignin and an Organosolv maple wood [47]. While oxidation of Kraft lignin delivered few percent of aromatic monomers (i.e., $9 \mathrm{wt} \%$ ), Organosolv lignin transformation produced yields up to $40 \mathrm{wt} \%$. The authors attributed this discrepancy to a better preservation of lignin "native" structure with Organosolv processes.

Palladium catalysts have also been considered in oxidative depolymerization; despite interesting results, they have only been sparsely studied. Recently, $\mathrm{Pd} / \mathrm{CeO}_{2}$ was described in oxidative depolymerization of an Organosolv lignin in methanol under oxygen at $458 \mathrm{~K}$ for $24 \mathrm{~h}$, delivering vanillin $(5.2 \mathrm{wt} \%)$, guaiacol $(0.9 \mathrm{wt} \%)$ and $p$-hydroxybenzaldehyde $(2.4 \mathrm{wt} \%)$ [48]. The group of Sales has probably studied Pd-based catalysts for the oxidative depolymerization of lignin the most Pd-based catalysts. Initially, authors reported the oxidative depolymerization of bagasse lignin, in the presence of $\mathrm{Pd} / \gamma-\mathrm{Al}_{2} \mathrm{O}_{3}$, clearly showing an increase of the yield in vanillin (0.2 wt \% to $2.5 \mathrm{wt} \%)$, syringaldehyde $(0.3 \mathrm{wt} \%$ to $3.6 \mathrm{wt} \%)$ and $p$-hydroxybenzaldehyde ( $0.6 \mathrm{wt} \%$ to $4.1 \mathrm{wt} \%)$. Kinetic model indicated that the catalyst did not play a role on lignin depolymerization but act in following transformations, mainly on degradation of the products [40].

Thus, from this literature brief overview, in the field of heterogeneous systems, beside metal oxide, supported noble metal represent an attractive area. We evaluated elsewhere the role of a $\mathrm{Pt} / \mathrm{ZrO} 2$ catalyst in lignin depolymerization to aromatics under supercritical conditions [49]. In this application, the $\mathrm{Pt} / \mathrm{ZrO}_{2}$ catalyst showed better results than their copper-based counterparts. Therefore, based on our previously reported studies showing that moderate yield in vanillin and/or syringaldehyde could be reached [13], the authors evaluated the use of a platinum and a gold-supported catalyst to improve the production of lignin-based aromatics. Based on our results, a kinetic model was developed to describe lignin oxidative depolymerization.

\section{Results and Discussion}

\subsection{Optimization of Key Reaction Parameters}

In a previous report, the authors described the evaluation of several reaction parameters relative to lignin oxidative depolymerization using Kraft lignin, namely the air pressure, base concentration and temperature [13]. Before performing a comprehensive study of the chosen catalysts' influence (i.e., $\mathrm{Au} / \mathrm{TiO}_{2}$ and $\mathrm{Pt} / \mathrm{TiO}_{2}$ ), the effect of these parameters on catalytic lignin oxidation was determined.

Lignin depolymerization was conducted in the presence of $\mathrm{NaOH}$ at a concentration of 1 and $10 \mathrm{~g} / \mathrm{L}$, showing interesting results (Figure 1). Indeed, lignin conversion (i.e., ca. 50\% at $1 \mathrm{~g} / \mathrm{L}$ and ca. $10 \%$ at $10 \mathrm{~g} / \mathrm{L}$ ) was not significantly affected by the catalysts, which was in contradiction with the observed yields of aromatic compounds recovered in the "DCM" fraction. This observation is in agreement with the conclusion made by Sales et al. stating that catalyst mainly reacts with the primary products of lignin oxidative depolymerization since the effect of both catalysts were only observed in the "DCM" fraction [50]. At $1 \mathrm{~g} / \mathrm{L}$, the presence of $\mathrm{Au} / \mathrm{TiO}_{2}$ provided a higher production of aromatics, especially for vanillic acid $(+0.5 \mathrm{wt} \%)$; however, only trace amounts of these compounds were recovered when $\mathrm{Pt} / \mathrm{TiO}_{2}$ was used, which can be attributed to enhanced over-oxidation reaction. 
Surprisingly, increasing the base concentration to $10 \mathrm{~g} / \mathrm{L}$ resulted in the opposite effect. While the presence of $\mathrm{Pt} / \mathrm{TiO}_{2}$ allowed for the recovery of $3 \mathrm{wt} \%$ of vanillin, oxidation delivered only $0.6 \mathrm{wt} \%$ of vanillin with $\mathrm{Au} / \mathrm{TiO}_{2}$ against $2.2 \mathrm{wt} \%$ in absence of any catalyst. To understand this effect, the authors performed a degradation experiment on vanillin with both catalysts at $10 \mathrm{~g} / \mathrm{L}$ (Figure S2). The kinetic constant for vanillin degradation reached $8.9 \mathrm{~h}^{-1}$ with $\mathrm{Au} / \mathrm{TiO}_{2}$ and $0.3 \mathrm{~h}^{-1}$ with $\mathrm{Pt} / \mathrm{TiO}_{2}$ against $0.1 \mathrm{~h}^{-1}$ without a catalyst. Therefore, it appeared that $\mathrm{Au} / \mathrm{TiO}_{2}$ was mainly involved in the over-oxidation of vanillin at $10 \mathrm{~g} / \mathrm{L}$ of $\mathrm{NaOH}$, which is not suitable for the production aromatics. Thus, this catalyst was not studied any further.
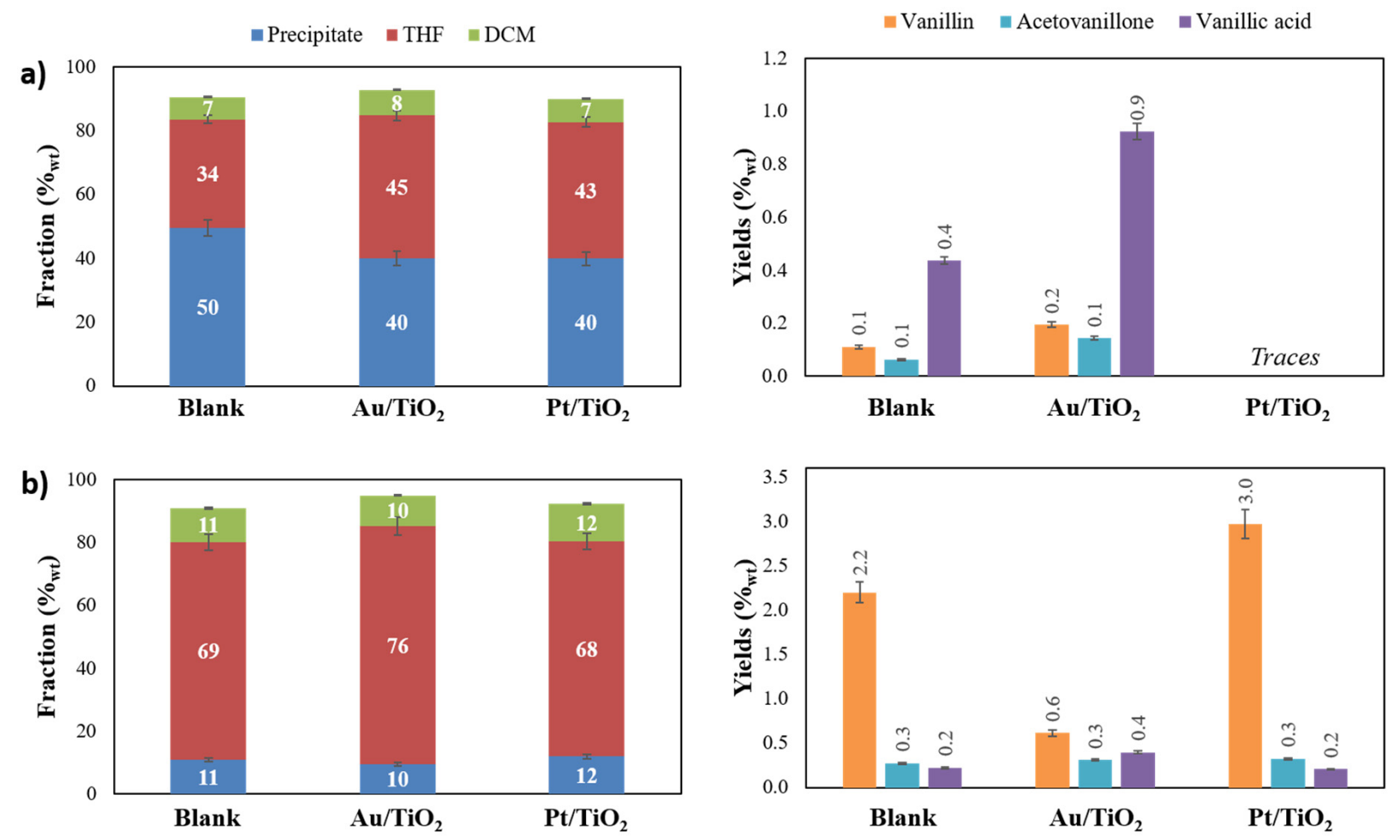

Figure 1. Influence of $\mathrm{NaOH}$ concentration in lignin oxidation by $\mathrm{Au} / \mathrm{TiO}_{2}$ and $\mathrm{Pt} / \mathrm{TiO}_{2}$ on lignin conversion and yields of the main aromatic compounds. Conditions: Kraft lignin, $150{ }^{\circ} \mathrm{C}, 1 \mathrm{~h}, \mathrm{P}_{\mathrm{air}}: 40$ bar; $\mathrm{C}_{\mathrm{NaOH}}: 1 \mathrm{~g} / \mathrm{L}$ (a) and $10 \mathrm{~g} / \mathrm{L}$ (b).

The influence of air pressure over lignin catalyzed depolymerization by $\mathrm{Pt} / \mathrm{TiO}_{2}$ was also evaluated (Figure 2). While the presence of the catalyst had almost no significant effect on the quantity of "DCM" and "THF" fractions retrieved, the amount of "precipitate" recovered increased by $12 \mathrm{wt} \%$ and $4 \mathrm{wt} \%$ at 10 and 20 bar respectively. However, the same effect was not observed when the experiment was done at 40 bar. While the role of catalyst is very limited on the quantity of three fractions obtained, its use modified the selectivity of aromatics, mainly improving yields of vanillin. Catalytic oxidation appeared to show the same trend displayed without catalyst, i.e., a rise of vanillin yield from 10 to 20 bar before slightly decreasing to 40 bar. Interestingly, the presence of $\mathrm{Pt} / \mathrm{TiO}_{2}$ did not improve the yield of vanillin at $10 \mathrm{bar}$ (ca. $2.6 \mathrm{wt} \%$ ) while it increased the selectivity towards vanillin when the reactions were realized at 20 bar (from $2.8 \mathrm{wt} \%$ to $3.4 \mathrm{wt} \%$ ) and $40 \mathrm{bar}$ (from $2.2 \mathrm{wt} \%$ to $3 \mathrm{wt} \%$ ). Noticeably, at a pressure of $10 \mathrm{bar}$, the yield of vanillic acid decreased from 1.7 to $1.2 \mathrm{wt} \%$ with $\mathrm{Pt} / \mathrm{TiO}_{2}$, therefore suggesting a difference of production mechanism by lignin oxidation of vanillin and vanillic acid already observed in our previous report [13]. 

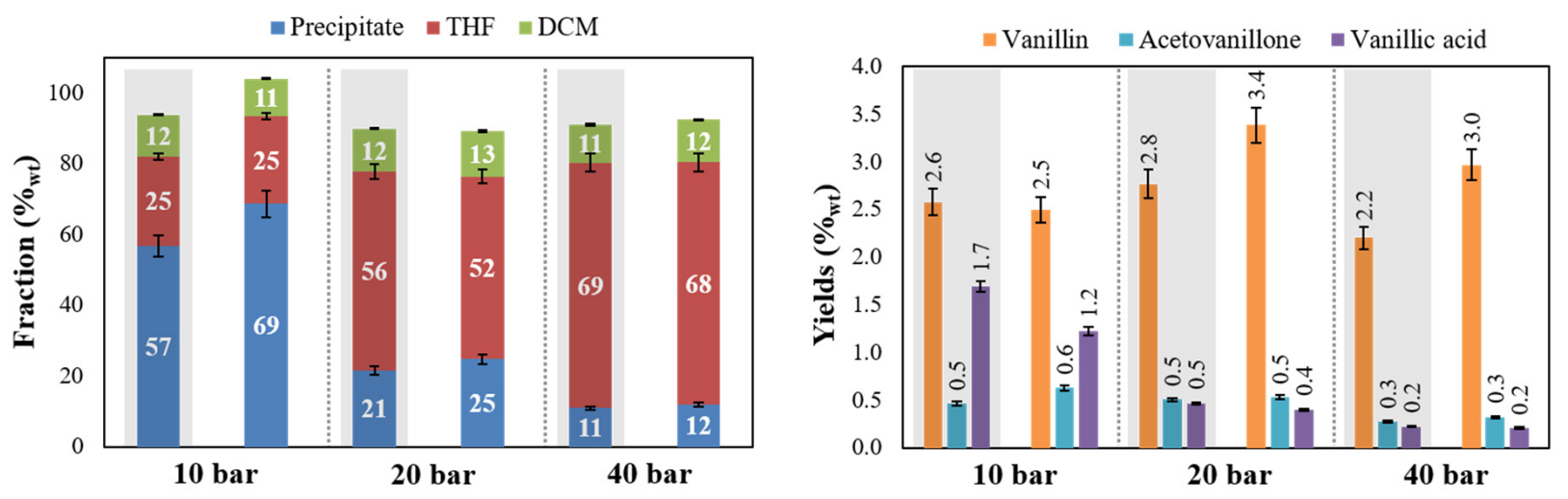

Figure 2. Influence of air pressure on Kraft lignin conversion and yields of the main aromatic compounds ( $\square$ : Non-catalytic). Conditions: $150{ }^{\circ} \mathrm{C}, 1 \mathrm{~h}, \mathrm{C}_{\mathrm{NaOH}}: 10 \mathrm{~g} / \mathrm{L}$.

Thus, following the preliminary evaluation of the reaction parameters, the following conditions were used in the remainder of this study to maximize vanillin production: $150{ }^{\circ} \mathrm{C}, \mathrm{P}_{\text {air }}=20 \mathrm{bar}, \mathrm{C}_{\mathrm{NaOH}}: 10 \mathrm{~g} / \mathrm{L}, \mathrm{C}_{\text {lignin }}: 5 \mathrm{~g} / \mathrm{L}$. Before studying lignin catalytic oxidation, the role of the support in the reaction was assessed (Figure S3). Depolymerization performed with $\mathrm{TiO}_{2}$ alone demonstrated that the support did not affected lignin oxidation as the results obtained were identical to those obtained without a catalyst. Therefore, it is reasonable to conclude that the supported Pt particles are responsible for the improvement observed. Interestingly, it has been demonstrated in other fields that the contribution of support was not very prominent when very active noble metal phases were used, which might explain this effect [51,52].

\subsection{Evaluating the Influence of Catalytic Lignin Oxidation}

In our previous work, the transformations of lignin brought by oxidative depolymerization were studied over $5 \mathrm{~h}$ using three lignins (i.e., Kraft, EOL-Ab, and EOL-As lignins) [13]. Among the observation made, it was shown that most of the modifications occurred within $1 \mathrm{~h}$; therefore, the influence of $\mathrm{Pt} / \mathrm{TiO}_{2}$ on lignin oxidation was investigated over $1 \mathrm{~h}$ using the same lignin samples.

The evolution of the fractions in absence and presence of catalyst, during oxidative depolymerization of the three lignins, is represented in Figure 3. The profiles displayed by catalytic oxidation were similar to those obtained without catalyst for all three lignins, which is in agreement with the hypothesis of Sales et al. [50] Noticeably, the difference in reactivity between softwood (Kraft, EOL-Ab) and hardwood lignins was also preserved, i.e., a higher depolymerization rate for EOL-As expressed by a lower amount of "precipitate". Nonetheless, the use of $\mathrm{Pt} / \mathrm{TiO}_{2}$ resulted in an increase of the quantity of "precipitate" recovered compared to non-catalytic reactions for all three lignins (i.e., Kraft- $39 \mathrm{wt} \% \mathrm{vs}$. $17 \mathrm{wt} \%$; EOL-Ab-34 wt $\%$ vs. $24 \mathrm{wt} \%$; EOL-As-22 wt $\%$ vs. $13 \mathrm{wt} \%)$. Likewise, catalytic oxidation allowed for a slight rise of the yields of "DCM" fraction (ca. $17 \mathrm{wt} \%$ vs. ca. $14 \mathrm{wt} \%)$. However, ca. 50-60 wt\% of "THF" fraction was recovered after non-catalytic oxidation while only ca. $40 \mathrm{wt} \%$ was obtained when $\mathrm{Pt} / \mathrm{TiO}_{2}$ was used. Noticeably, the amount of "THF" fraction reached its maximum after $30 \mathrm{~min}$ with the catalyst while it took $1 \mathrm{~h}$ without. 

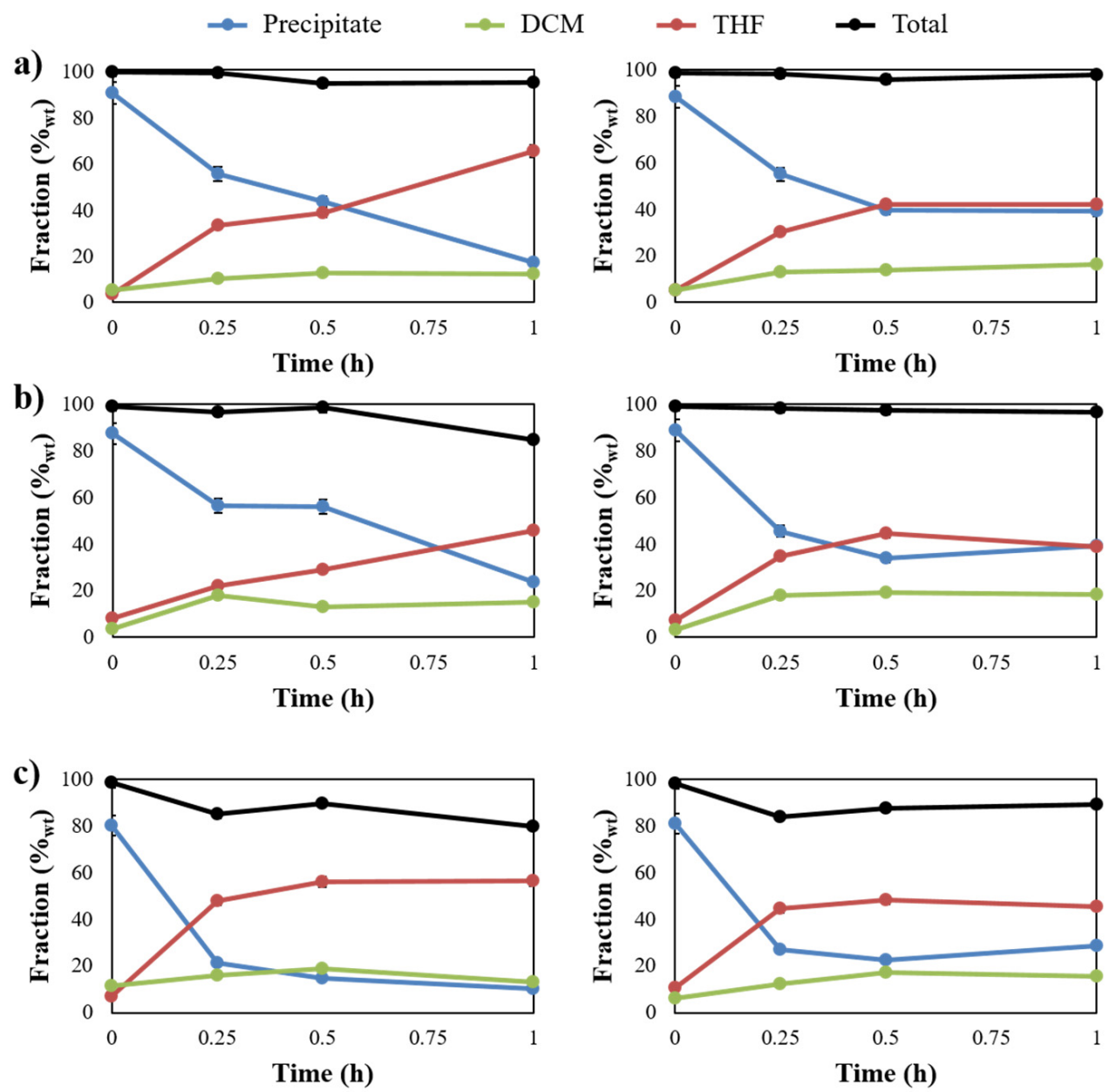

Figure 3. Evolution of the three product fractions (i.e., precipitate, DCM and THF) versus time during non-catalytic (left) and catalytic (right) oxidation for Kraft (a), EOL-Ab (b) and EOL-As (c) lignins.

Analysis of the "DCM" fractions recovered for all lignins is represented in Figure 4. Given their relative botanical nature, Kraft and EOL-Ab lignins showed only aromatic compounds derived from guaiacyl units, whereas EOL-As lignin produced aromatic products related to guaiacyl and syringyl units. Catalyzed and non-catalyzed oxidation displayed the same behavior with a fast production of the aromatic compounds within the first 30 min of reaction; however, the yields of aromatic obtained were mainly higher with the catalyst, especially for aldehyde adducts. For Kraft and EOL-Ab lignins, yields of vanillin increased to $3.4 \mathrm{wt} \%$ and $5.1 \mathrm{wt} \%$, resp. after $30 \mathrm{~min}$ (vs. $2.4 \mathrm{wt} \%$ and $4.5 \mathrm{wt} \%$, resp. without catalyst). EOL-As lignin's catalytic oxidation resulted in the recovery of $1.7 \mathrm{wt} \%$ of vanillin and $6 \mathrm{wt} \%$ of syringaldehyde (vs. $1.6 \mathrm{wt} \%$ and $3.0 \mathrm{wt} \%$, resp.) after $30 \mathrm{~min}$. While less remarkable, yields of aromatic ketones were increased as well from ca. $0.4 \mathrm{wt} \%$ to ca. $1 \mathrm{wt} \%$ for all lignins. However, acid aromatics production slightly decreased for softwood lignins by ca. $0.3 \mathrm{wt} \%$ while they increased from $0.4 \mathrm{wt} \%$ to $0.9 \mathrm{wt} \%$ for EOL-As. Thus, the presence of $\mathrm{Pt} / \mathrm{TiO}_{2}$ allowed for the recovery of mono-aromatics with higher efficiency in a media where over-oxidation reactions occur. Interestingly, the catalytic degradation of vanillin and syringaldehyde demonstrated that they were not strongly affected by $\mathrm{Pt} / \mathrm{TiO}_{2}$, especially for syringaldehyde, which displayed a degradation kinetic constant of ca. $1.9 \mathrm{~h}^{-1}$ with and without catalyst (Figure S2). This would explain the higher improvement of syringaldehyde yields observed. 

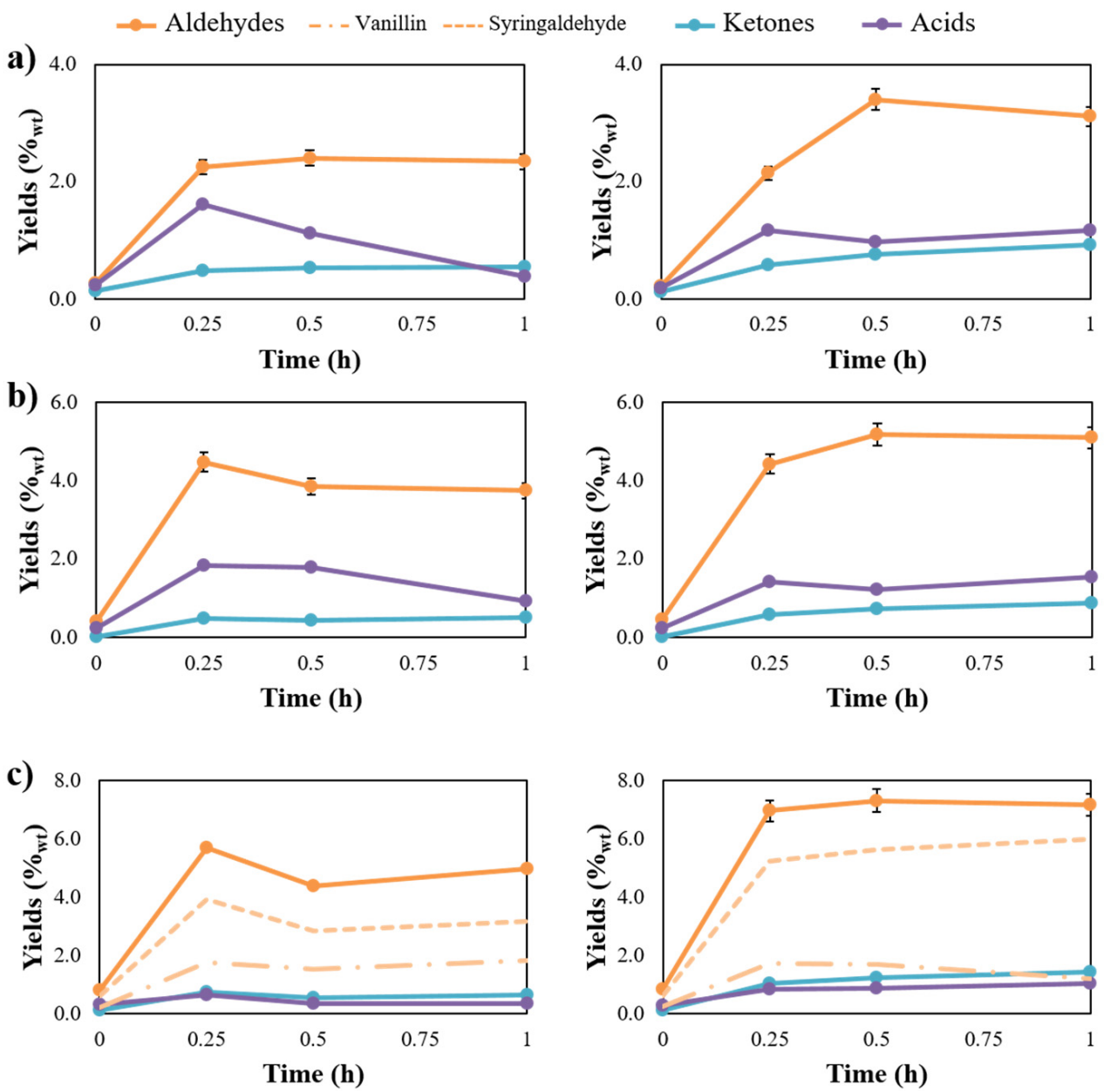

Figure 4. Evolution of the yields of the main aromatic compounds in "DCM" fraction during noncatalytic (left) and catalytic (right) oxidation for Kraft (a), EOL-Ab (b) and EOL-As (c) lignins. Aldehydes, ketones and acids equal to vanillin, acetovanillone and vanillic acid resp. for softwood lignins.

Analysis of the "precipitate" fractions was performed by complementary techniques to obtain better insights into the transformations resulting from catalyzed lignin oxidation. HSQC NMR enabled the evaluation of modifications related to lignin sub-structures and aromatic rings over time. Firstly, the effect of the catalyst was evaluated during the heating phase of the reactor, showing the same modifications observed without catalyst, i.e., disappearance of cinnamyl-type sub-structures and residual carbohydrates in the initial lignins (Figures S5-S8). Similarly to the non-catalyzed oxidation, loss of the signals attributed to $p$-hydroxybenzyl units as well as the appearance of correlations corresponding to guaiacyl and syringyl units substituted by carbonyl groups could be observed for all lignin after $15 \mathrm{~min}$ of reaction (Figures S6-S8). In the same manner, the formation of conjugated olefins was detected probably due to ring-opening reactions [13] which can also be observed in other studies [53,54]. Most importantly, the use of $\mathrm{Pt} / \mathrm{TiO}_{2}$ exhibited interesting results on correlations linked to inter-units $\beta-O-4\left(\mathbf{A} / \mathbf{A}^{\prime} / \mathbf{A}^{\prime \prime}\right), \beta-\beta(\mathbf{B})$ and $\beta-5$ (C). In our previous study, the analysis revealed the disappearance of the correlations linked to inter-unit $\beta-\beta$ (B) and $\beta-5$ (C) bonds in softwood lignin after 30 to $60 \mathrm{~min}$ of reaction time [13]. However, these same signals remained observable after $1 \mathrm{~h}$ under catalyzed oxidation, except for EOL-As, which displayed a loss of $\mathbf{C}$ signals $\left(\mathbf{C}_{\alpha}: \delta_{\mathrm{H}} / \delta_{\mathrm{C}^{-}}\right.$ $5 ; 49 / 87.6 \mathrm{ppm} ; \mathrm{C}_{\beta}: \delta_{\mathrm{H}} / \delta_{\mathrm{C}}-3.47 / 53.96 \mathrm{ppm}$ ) after $15 \mathrm{~min}$ (Figure 5). The semi-quantitative analyses supported the observations (Figure S9). Previous reports have demonstrated a direct relationship between the yields of aromatic compounds and lignin's structure, in particular its integrity $[13,15,55]$. The results presented here tend to reinforce this 
hypothesis since the rise of aromatics recovered by catalytic oxidation is correlated to a higher retention of lignin's structure and more specifically its inter-unit bonds.

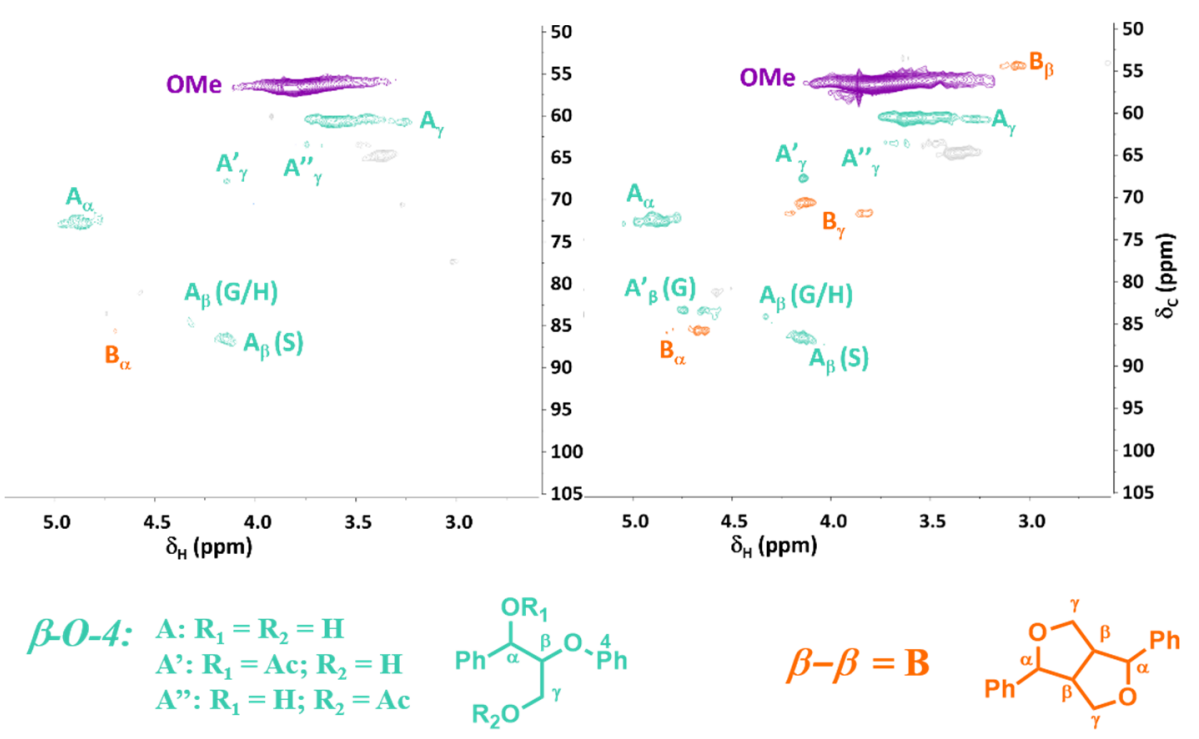

Figure 5. HSQC NMR spectra of EOL-As lignin (Aromatic region) versus time (see Figures S6-S8 for HSQC spectra of other lignins).

To gather additional insights into lignin oxidation by $\mathrm{Pt} / \mathrm{TiO}_{2}$, "precipitate" fractions were analyzed by ${ }^{31} \mathrm{P}$ NMR analyses to follow the evolution of accessible hydroxyl groups over time (Figure 6). In our previous report, a direct correlation between the concentration of guaiacyl and syringyl $\mathrm{OH}$ and the amount of "precipitate" recovered over time was demonstrated [13]. The results, obtained under catalysis, tend to confirm this relationship since higher concentrations of guaiacyl and syringyl $\mathrm{OH}\left(\mathrm{ca} .+0.4 \mathrm{mmol} \mathrm{OH} / \mathrm{g}_{\text {Lignin }}\right.$ ) after $1 \mathrm{~h}$ could be linked to higher "precipitate" yields for each lignin. Therefore, the accessible phenolic groups appear to be at the origin of the depolymerization even with the catalyst; this suggests, once again, that $\mathrm{Pt} / \mathrm{TiO}_{2}$ reacts with primary products of lignin oxidative depolymerization.

Finally, under catalysis, the evolution of carboxylic $\mathrm{OH}$ was also modified. They increased from ca. 0.4 to ca. $1.5 \mathrm{mmol} \mathrm{OH} / \mathrm{g}_{\text {Lignin }}$ after $30 \mathrm{~min}$ before decreasing to ca. $1.2 \mathrm{mmol} \mathrm{OH} / \mathrm{g}_{\text {Lignin }}$ after $1 \mathrm{~h}$ while, they rose up to ca. $1.9 \mathrm{mmol} \mathrm{OH} / \mathrm{g}_{\text {Lignin }}$ after $1 \mathrm{~h}$ under non-catalytic conditions. This diminishing production of carboxylic $\mathrm{OH}$, related to ring-opening reactions, demonstrated the ability of $\mathrm{Pt} / \mathrm{TiO}_{2}$ to drive the selectivity of lignin oxidation towards a less destructive route for the aromatic units, thus preserving its structure and increase the production of the targeted compounds.

\subsection{Development of A Kinetic Model}

In an attempt to rationalize all observations made, kinetic models were constructed to describe the evolution of the products obtained by lignin oxidative depolymerization and their relationship to one another. Fortunately, the development of the fractionation process helped us, despite the high complexity of lignin oxidation products, isolate three distinct fractions with specific features and allowed us to evaluate the lignin oxidation mechanism. Generally, it is considered that lignin oxidation proceeds through a cleavage of the interunits to produce small aromatic aldehydes followed by the degradation of these compounds into smaller aliphatic and volatile compounds (Figure 7a) [50]. However, the presence of conjugated aliphatic within the "precipitate" structure, suggesting a degradation of the aromatic rings, lead us to believe that smaller aliphatics were also produced directly from compounds with greater molecular weight (Figure $7 \mathrm{~b}$ ). Therefore, two kinetic models were constructed to represent these two approaches so that their validity could be assessed. For these models, it is assumed that lignin oxidation follows a first order kinetic. 
$\rightarrow \mathrm{OH}_{\text {Guaiacyl }}^{\rightarrow} \mathrm{OH}_{\text {Syringyl+condensed }} \rightarrow \mathrm{OH}_{\text {Carboxylic acid }}$
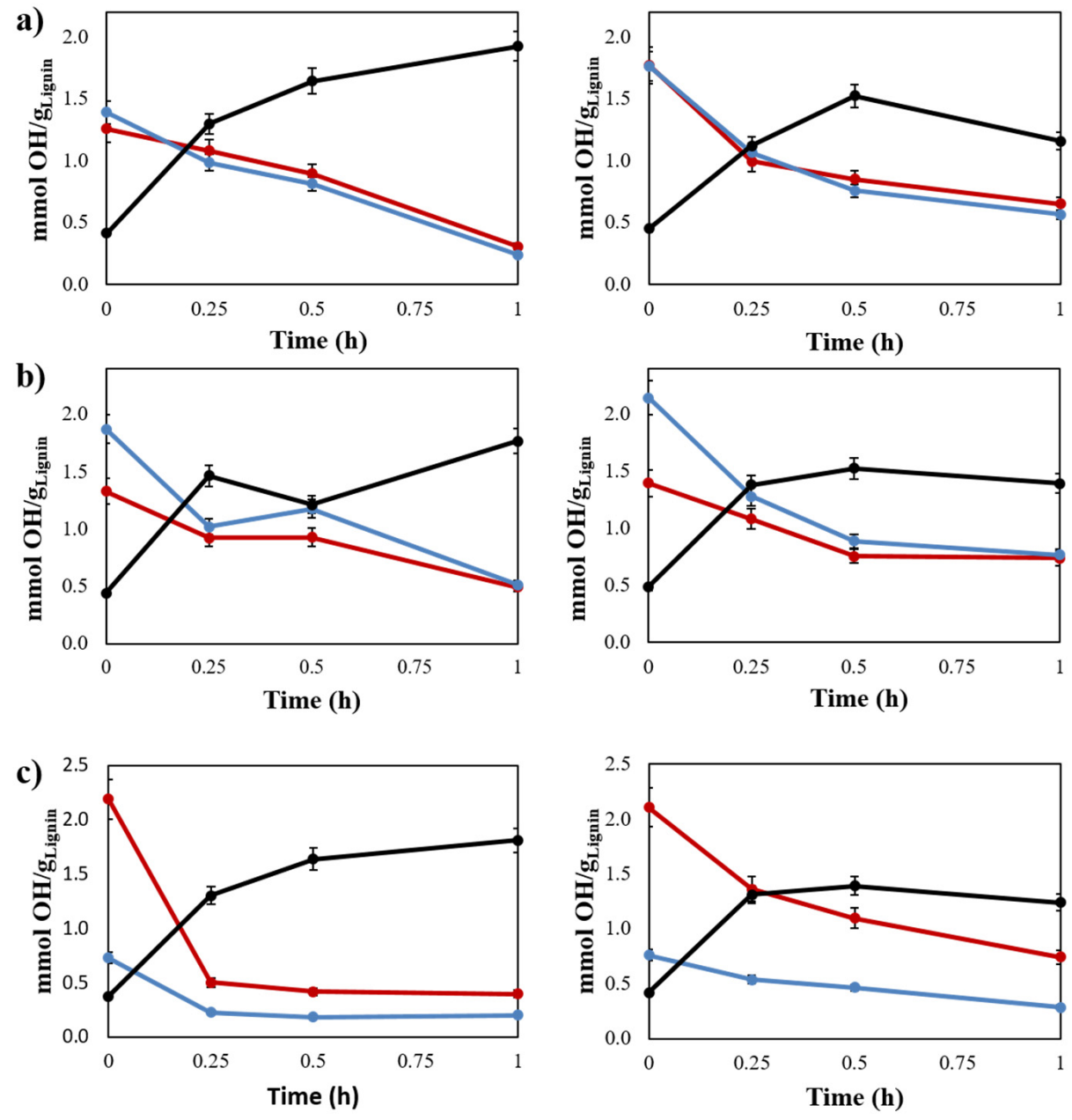

Figure 6. (a-c) Evolution of the available $\mathrm{OH}$ functions encountered on the "precipitate" over time by ${ }^{31} \mathrm{P}$ NMR spectra for Kraft, EOL-Ab and EOL-As lignins.
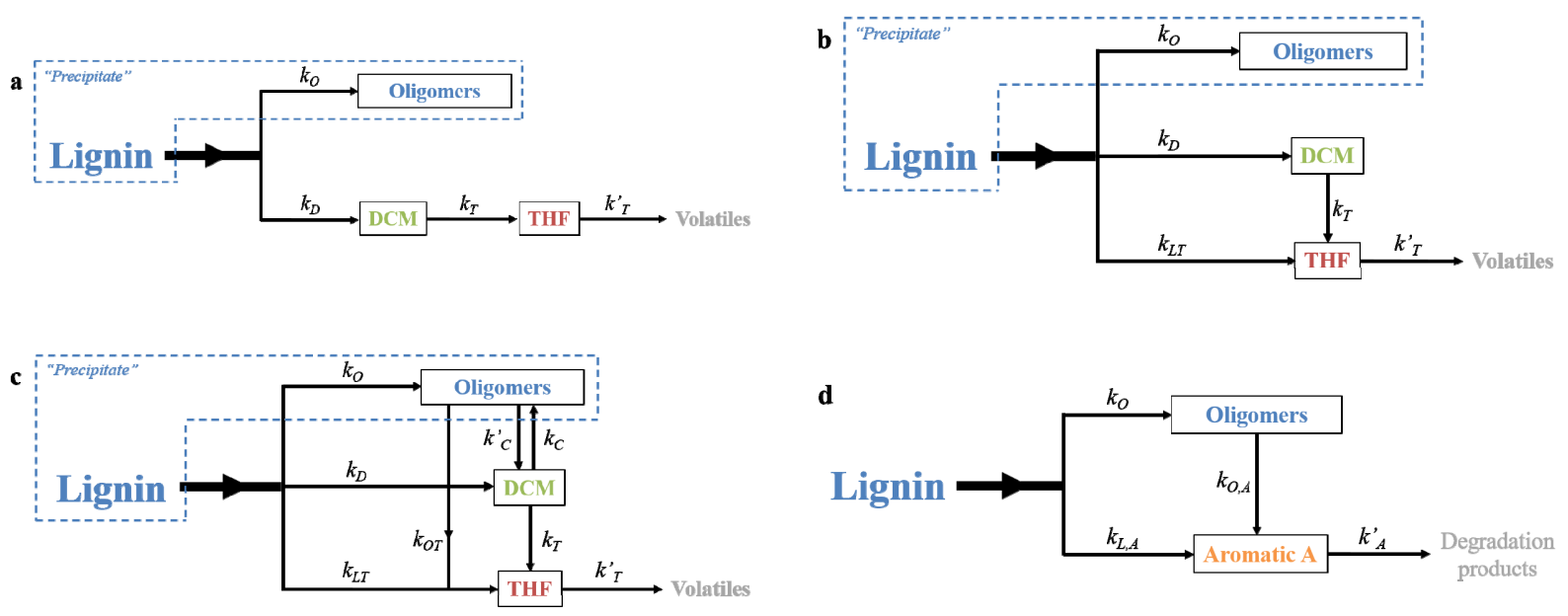

Figure 7. Schematic representation of the kinetic models. Route (a): lignin oxidation to aromatic aldehydes followed by degradation to aliphatics and volatiles. Route $(\mathbf{b})$ : lignin oxidation to aromatics followed by degradation of the aromatic rings. Route (c): lignin oxidation to aromatics followed by oligomers formation before subsequent depolymerization. Route (d): lignin oxidation to lighter oligomers before generating aromatics. 
The results obtained from the first model displayed an inability to reconcile the formation of small aromatics ("DCM") and aliphatics ("THF") at the same time, probably due to the high amount of small aliphatics recovered (Figure S10). Thereby, the simultaneous production of both fractions from lignin oxidation seems to be the correct hypothesis. The patterns exhibited by the monitoring of the fraction over time, as well as the aliphatic sub-structures detected, tend to corroborate this conclusion. While the inclusion of the simultaneous production into the second model allowed for a better representation of the experimental data, a discrepancy between the predicted and experimental data was still observed. Indeed, the predicted "THF" value were overestimated, leading to improbable mass balances (Figure S10). Therefore, the resulting inaccuracy of this model highlighted the need to consider another parameter.

In their study, Zhu et al. performed oxidation of vanillin to observe study in its degradation behavior under lignin alkaline oxidation conditions [56]. Through several analytical techniques, they identified condensed dimers among the main products of vanillin oxidation. Therefore, it can be assumed that condensation reactions also occurred during lignin oxidative depolymerization; these types of reaction have been described in pulping processes (i.e., high alkaline media). Thus, a third model was developed to include condensation reactions of small aromatic compounds ("DCM") into oligomers before subsequent depolymerization reactions (Figure 7c). Inclusion of condensation reactions resulted in a great representation of the experimental data obtained by lignin oxidative depolymerization. Therefore, the analysis of the results given by the model will be discussed, starting with the evolution of the three fractions over time during lignin oxidation, which are described by Equations (1)-(4):

$$
\begin{gathered}
\frac{d[\text { Lignin }]}{d t}=-\bar{k}[\text { Lignin }] \\
\frac{d[\text { Oligomer }]}{d t}=\bar{k}_{O}[\text { Lignin }]+\bar{k}_{C}[D C M]-\bar{k}_{C}^{\prime}[\text { Oligomer }] \\
\frac{d[D C M]}{d t}=\bar{k}_{D}[\text { Lignin }]+\bar{k}_{C}^{\prime}[\text { Oligomer }]-\left(\bar{k}_{C}+\bar{k}_{T}\right)[D C M] \\
\frac{d[T H F]}{d t}=\left(\bar{k}_{L T}+\bar{k}_{O T}\right)[\text { Lignin }]+\bar{k}_{T}[D C M]-\bar{k}_{T}^{\prime}[T H F]
\end{gathered}
$$

where $\bar{k}_{O}, \bar{k}_{D}, \bar{k}_{L T}$ represent the production of oligomer, small aromatic ("DCM") and aliphatic ("THF") compounds from lignin, respectively; $\bar{k}\left(=\bar{k}_{O}+\bar{k}_{D}+\bar{k}_{L T}\right)$ is related to lignin's degradation; $\bar{k}_{C}$ portrays the formation of condensed compounds from small aromatics ("DCM"); $\bar{k}_{C}^{\prime}$ outlines the degradation of oligomer into aromatics ("DCM"); $\bar{k}_{T}$ illustrate the degradation of aromatics ("DCM") into aliphatics ("THF"); and $\bar{k}_{T}^{\prime}$ is the degradation of aliphatics ("THF") into volatile compounds.

Comparison of the experimental and simulated data for EOL-As catalytic oxidation (Figure 8) demonstrates a satisfactory fitting of the model. Likewise, the parity plot shows the same outcome for the evolution of the three fractions recovered after oxidation with and without catalysts for each lignin. Consequently, the model developed seems to validate the hypotheses made throughout our study, e.g., the production of small aliphatics directly from lignin's aromatic degradation and the existence of condensation reactions between small aromatics. Noticeably, the authors assume that condensation reactions also occur for larger aromatics but are, alas, not quantifiable with our approach. 

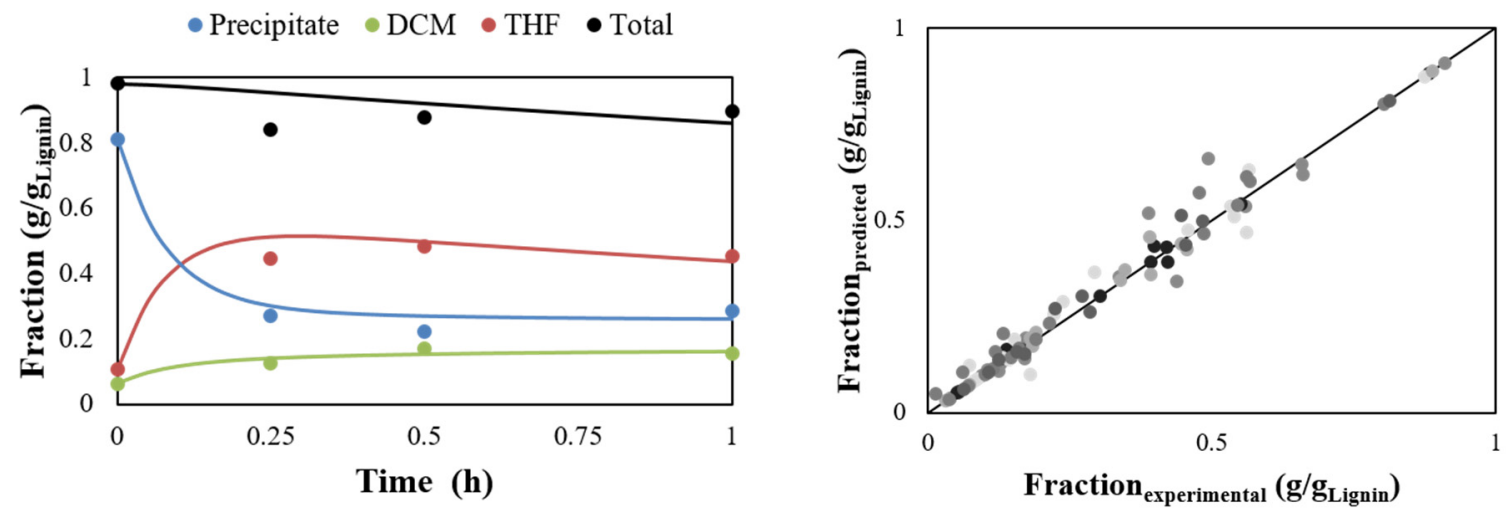

Figure 8. Evolution of the three fractions versus time for EOL-As lignin oxidation (left; see Figures S11 and S12 for the modeling of catalytic and non-catalytic oxidation of the other lignins) and parity plot comparing the model to experimental data for all lignins with and without catalyst (right). Data: $(-)$ model, $(\bullet)$ experimental.

Determination of the kinetic constants related to lignin non-catalytic oxidative depolymerization permitted support of the trends observed to expand our knowledge (Table 1). Primarily, softwood and hardwood lignins' differences of reactivity towards oxidation was verified by the model. Indeed, a higher depolymerization rate was displayed for EOL-As lignin $\left(\bar{k}=9.1 \mathrm{~h}^{-1}\right.$ vs. $\left.1.89-2.54 \mathrm{~h}^{-1}\right)$. The high sensitivity of hardwood lignins was also demonstrated by the production of oligomers $\left(\bar{k}_{O}: 2.17 \mathrm{~h}^{-1}\right.$ vs. ca. $\left.0.26-0.5 \mathrm{~h}^{-1}\right)$, small aliphatics $\left(\bar{k}_{L T}: 6.56 \mathrm{~h}^{-1}\right.$ vs. $\left.1.07-1.95 \mathrm{~h}^{-1}\right)$ and volatile compounds $\left(\bar{k}_{T}^{\prime}: 0.14 \mathrm{vs}\right.$. $\left.0.05-0.1 \mathrm{~h}^{-1}\right)$. However, lignin's botanical nature did not appear to have a significant effect on the formation of small aromatics $\left(\bar{k}_{D}: 0.41-0.54 \mathrm{~h}^{-1}\right)$. Considering condensation reactions, a difference between $\operatorname{kraft}\left(\bar{k}_{C} / \bar{k}_{C}^{\prime}: 1.2 \mathrm{~h}^{-1}\right)$ and EOL $\left(\bar{k}_{C} / \bar{k}_{C}^{\prime}: 0.3-0.5 \mathrm{~h}^{-1}\right)$ lignins was observed suggesting an effect of the extraction process. Ultimately, the model shows that lignin oxidative depolymerization is mostly driven by the degradation of aromatic units within the lignin's structure, which is consistent with the observation made on the "precipitate", namely the conjugated aliphatic substructures (HSQC NMR) and, most specifically, the high concentration of carboxylic acid ( ${ }^{31} \mathrm{P}$ NMR). More importantly, it demonstrates the shortcomings that need to be overcome to produce bio-based aromatics from lignin oxidation.

Table 1. Kinetic rate constants representing the evolution of each fraction during lignin (catalytic) oxidation ${ }^{\text {a }}$.

\begin{tabular}{|c|c|c|c|c|c|c|}
\hline & \multicolumn{6}{|c|}{ Kinetic Constant $\left(\mathrm{h}^{-1}\right)$} \\
\hline & \multicolumn{2}{|c|}{ Kraft } & \multicolumn{2}{|c|}{ EOL-Ab } & \multicolumn{2}{|c|}{ EOL-As } \\
\hline & $\bar{k}$ & $\bar{k}_{P t}$ & $\bar{k}$ & $\bar{k}_{P t}$ & $\bar{k}$ & $\bar{k}_{P t}$ \\
\hline $\bar{k}_{O}$ & 0.26 & 1.72 & 0.50 & 1.77 & 2.17 & 4.41 \\
\hline $\bar{k}_{D}$ & 0.41 & 0.69 & 0.38 & 1.60 & 0.54 & 1.18 \\
\hline $\bar{k}_{L T}$ & 1.87 & 1.87 & 1.01 & 2.59 & 6.39 & 7.04 \\
\hline $\bar{k}_{O T}$ & 0 & 0.002 & 0.016 & 0.004 & 0 & 0 \\
\hline $\bar{k}$ & 2.54 & 4.29 & 1.89 & 5.96 & 9.10 & 12.63 \\
\hline $\bar{k}_{C}$ & 0.63 & 0.41 & 0.45 & 0.83 & 0.34 & 1.55 \\
\hline $\bar{k}_{C}^{\prime}$ & 0.51 & 0.11 & 0.86 & 0.21 & 1.26 & 0.98 \\
\hline $\bar{k}_{C} / \bar{k}_{C}^{\prime}$ & 1.2 & 3.9 & 0.5 & 3.9 & 0.3 & 1.6 \\
\hline $\bar{k}_{T}$ & 0.12 & 0 & 0.24 & 0 & 0.26 & 0 \\
\hline $\bar{k}_{T}^{\prime}$ & 0.05 & 0.002 & 0.10 & 0.004 & 0.14 & 0.26 \\
\hline$\left(\bar{k}_{O}+\bar{k}_{D}\right) /\left(\bar{k}_{L T}+\bar{k}_{O T}\right)$ & 0.4 & 1.3 & 0.9 & 1.3 & 0.4 & 0.8 \\
\hline$\overline{\boldsymbol{k}}_{C} / \overline{\boldsymbol{k}}_{C}^{\prime}$ & 1.2 & 3.9 & 0.5 & 3.9 & 0.3 & 1.6 \\
\hline
\end{tabular}

a Conditions: T: $150{ }^{\circ} \mathrm{C}, \mathrm{P}_{\text {air }}: 20$ bar, $\mathrm{C}_{\mathrm{NaOH}}: 10 \mathrm{~g} / \mathrm{L}, 1 \mathrm{~h}, \mathrm{Pt} / \mathrm{TiO}_{2}: \mathrm{m}_{\mathrm{Pt}} / \mathrm{m}_{\text {Lignin }}=0.1 \mathrm{wt} \%$, 
Regarding lignin oxidation with $\mathrm{Pt} / \mathrm{TiO}_{2}$, evaluation of the kinetic constants displayed a rise of the depolymerization rate, which is translated into an increase of the production of oligomer, aromatic ("DCM") and aliphatic compounds ("THF"). However, the catalyst shows an ability to improve the ratio between the production of smaller aromatics $\left(\bar{k}_{O}+\bar{k}_{D}\right)$ and the degradation of aromatic moieties $\left(\bar{k}_{L T}+\bar{k}_{O T}\right)$. In the same manner, the use of $\mathrm{Pt} / \mathrm{TiO}_{2}$ appeared to promote condensation reactions, especially for softwood lignins $\left(\bar{k}_{C} / \bar{k}_{C}^{\prime}: 3.9 \mathrm{~h}^{-1}\right.$ vs. $\left.1.6 \mathrm{~h}^{-1}\right)$. These reactions were likely responsible for the decrease in aromatic degradation and volatiles production. They also explain the recovery of the higher amount of "precipitate" with the catalyst (Figures 2 and 3). The preservation of the lignin's structure detected by HSQC NMR could, therefore, be the result of a higher condensation rate. In the same manner, condensation could explain the lower concentrations of carboxylic acid analyzed by ${ }^{31}$ P NMR with the catalyst (Figure 6).

The evolution of vanillin, acetovanillone, vanillic acid, syringaldehyde and acetosyringone was also considered in the kinetic model (Figure 7d). In this model, the production of these molecules was considered to stem from the oxidation of the "precipitate" fraction (i.e., lignin and oligomer). Condensation products were regarded as degradation products since the structure reported by Zhu et al. are likely unable to produce the aforementioned molecules. In the eventuality that this route is possible, the authors hypothesized that it is negligible [56]. Therefore, the production and degradation of an aromatic product " $A$ " was described by Equation (5):

$$
\frac{d[A]}{d t}=\bar{k}_{L, A}[\text { Lignin }]+\bar{k}_{O, A}[\text { Oligomer }]-\bar{k}_{A}^{\prime}[A]
$$

where " $A$ " is one of the aromatic; $\bar{k}_{A}^{\prime}$ represents its degradation (condensation and ringopening); $\bar{k}_{L, A}$ and $\bar{k}_{O, A}$ depict its production from lignin and oligomer, respectively.

The model displayed a great representation of the evolution of the aromatic yields over time for all three lignins with and without catalyst (Figure 9). The aromatics' production and degradation processes portrayed by the kinetic constants (Table 2) were consistent with the observation made with lignin oxidation and aromatic degradation experiments (Figure S2). Noticeably, the degradation kinetic constants $\left(\bar{k}_{A}^{\prime}\right)$ displayed values in the same order of magnitude as those obtained for the degradation of vanillin $\left(0.17-0.32 \mathrm{~h}^{-1} \mathrm{vs}\right.$. $\left.0.1 \mathrm{~h}^{-1}\right)$ and syringaldehyde $\left(1.84 \mathrm{~h}^{-1}\right.$ vs. $\left.1.8 \mathrm{~h}^{-1}\right)$, thus showing syringyl-type compounds' high sensitivity towards oxidation. Furthermore, they are also in agreement with the results reported by Casimiro et al., which showed a higher degradation rate for carboxylic acid aromatics (vanillic acid: $6.19-12 \mathrm{~h}^{-1}$ ) followed by ketone aromatics (acetovanillone: $0.28-0.78 \mathrm{~h}^{-1}$ ) and finally aldehyde aromatics (vanillin: $0.17-0.32 \mathrm{~h}^{-1}$ ) [57].
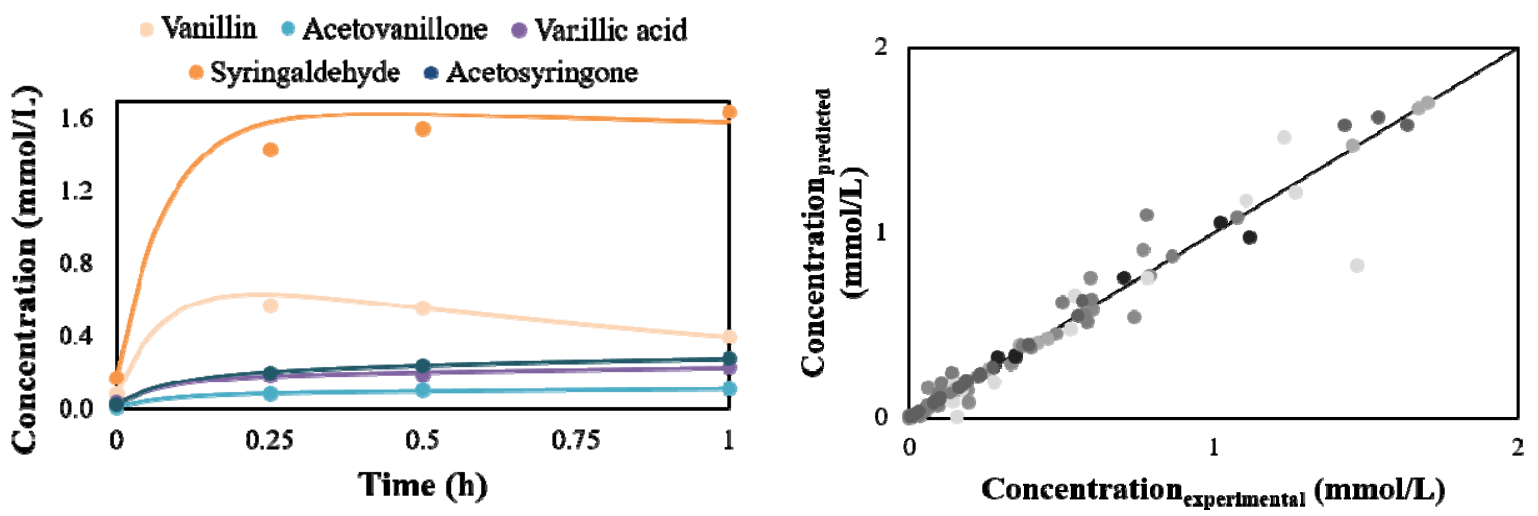

Figure 9. Evolution of the yields of aromatics versus time for EOL-As lignin catalytic oxidation (left; see Figures S11 and S12 for the modeling of the aromatic yields for catalytic and non-catalytic oxidation of the other lignins) and parity plot comparing the model to experimental data for all lignins with and without catalyst (right). Data: $(-)$ model, $(\bullet)$ experimental. 
Table 2. Kinetic constants representing the production and consumption of each aromatic compounds identified $^{\mathrm{a}}$.

\begin{tabular}{|c|c|c|c|c|c|c|c|}
\hline & & \multicolumn{6}{|c|}{ Kinetic Constant $\left(k \cdot 10^{2} \cdot \mathrm{h}^{-1}\right)$} \\
\hline & & \multicolumn{2}{|c|}{ Kraft } & \multicolumn{2}{|c|}{ EOL-Ab } & \multicolumn{2}{|c|}{ EOL-As } \\
\hline & & $\bar{k}$ & $\bar{k}_{P t}$ & $\bar{k}$ & $\bar{k}_{P t}$ & $\bar{k}$ & $\bar{k}_{P t}$ \\
\hline \multirow{4}{*}{$\begin{array}{l}\text { Vanillin } \\
\text { (V) }\end{array}$} & $\bar{k}_{O, V}$ & 0.02 & 0.05 & 0.00 & 0.20 & 0.19 & 0.005 \\
\hline & $\bar{k}_{L, V}$ & 9.6 & 17.0 & 13.4 & 39.1 & 17.4 & 31.0 \\
\hline & $\bar{k}^{\prime} V$ & 17.4 & 23.3 & 22.2 & 52.2 & 32.0 & 70.9 \\
\hline & $\bar{k}_{O, A c}$ & 0.09 & 0.06 & 0.07 & 0.07 & 0.03 & 0.03 \\
\hline \multirow[t]{3}{*}{ Acetovanillone (Ac) } & $\bar{k}_{L, A c}$ & 1.88 & 3.38 & 1.54 & 4.69 & 1.54 & 3.33 \\
\hline & $\bar{k}_{A c}^{\prime}$ & 77.7 & 69.4 & 75.0 & 76.8 & 27.3 & 57.8 \\
\hline & $\bar{k}_{O, V A}$ & 0.68 & 1.04 & 0.00 & 1.10 & 0.00 & 0.07 \\
\hline \multirow[t]{3}{*}{ Vanillic acid (VA) } & $\bar{k}_{L, V A}$ & 31.8 & 18.0 & 32.6 & 19.3 & 7.3 & 6.5 \\
\hline & $\bar{k}^{\prime} V A$ & 1201 & 1218 & 887 & 898 & 67.3 & 61.9 \\
\hline & $\bar{k}_{O, S}$ & - & - & - & - & 1.15 & 1.16 \\
\hline \multirow[t]{3}{*}{ Syringaldehyde (S) } & $\bar{k}_{L, S}$ & - & - & - & - & 36.6 & 69.7 \\
\hline & $\bar{k}_{S}^{\prime \prime}$ & - & - & - & - & 184 & 198 \\
\hline & $\bar{k}_{O, A S}$ & - & - & - & - & 0.00 & 0.13 \\
\hline \multirow[t]{2}{*}{ Acetosyringone (AS) } & $\bar{k}_{L, A S}$ & - & - & - & - & 5.0 & 7.3 \\
\hline & $\bar{k}_{A S}^{\prime}$ & - & - & - & - & 103 & 112 \\
\hline
\end{tabular}

a Conditions: T: $150{ }^{\circ} \mathrm{C}, \mathrm{P}_{\text {air }}: 20$ bar, $\mathrm{C}_{\mathrm{NaOH}}: 10 \mathrm{~g} / \mathrm{L}, 1 \mathrm{~h}, \mathrm{Pt} / \mathrm{TiO}_{2}: \mathrm{m}_{\mathrm{Pt}} / \mathrm{m}_{\mathrm{Lignin}}=0.1 \mathrm{wt} \%$.

The kinetic constants uncovered for lignin catalytic oxidation also appear to be in accordance with our experiments (Figure S2). A significant increase of vanillin's degradation kinetic constants $\left(\bar{k}_{V}^{\prime}\right.$ : $0.17-0.32 \mathrm{~h}^{-1}$ vs. $\left.0.23-0.71 \mathrm{~h}^{-1}\right)$ was observed for each lignin while syringaldehyde $\left(\bar{k}_{S}^{\prime}: 1.84 \mathrm{~h}^{-1}\right.$ vs. $\left.1.98 \mathrm{~h}^{-1}\right)$ was only slightly more degraded by $\mathrm{Pt} / \mathrm{TiO}_{2}$. Nevertheless, the catalyst allowed for a greater rise of the production rate, which resulted in higher yields of aromatics (Table 3). The ratios between production and degradation was improved for all compounds (from $+20 \%$ to $+200 \%$ ) during lignin catalytic oxidation with some exceptions. In contrast to the other aromatics, the ratios observed for vanillic acid decreased (from $-33 \%$ to $-50 \%$ ) slightly or remained the same. This behavior might substantiate the hypothesis that vanillic acid is produced from a mechanism separate from vanillin and acetovanillone. Noticeably, EOL-As catalytic oxidation resulted in a slight decrease of the production/degradation ratio of vanillin $(-20 \%)$, which might be attributed to a low amount of guaiacyl unit (Figure 6). Similarly, the same explanation can be imputed to the ratio observed for acetovanillone.

Table 3. Production/degradation ratios of the aromatic compounds identified ${ }^{\mathrm{a}}$.

\begin{tabular}{ccccccc}
\hline & \multicolumn{2}{c}{ Kraft } & \multicolumn{2}{c}{ EOL-Ab } & \multicolumn{2}{c}{ EOL-As } \\
\hline & $\overline{\boldsymbol{k}}$ & $\overline{\boldsymbol{k}}_{\boldsymbol{P t}}$ & $\overline{\boldsymbol{k}}$ & $\overline{\boldsymbol{k}}_{\boldsymbol{P t}}$ & $\overline{\boldsymbol{k}}$ & $\overline{\boldsymbol{k}}_{\boldsymbol{P t}}$ \\
\hline Vanillin & 0.55 & 0.73 & 0.60 & 0.75 & 0.55 & 0.44 \\
Acetovanillone & 0.03 & 0.05 & 0.02 & 0.06 & 0.06 & 0.06 \\
Vanillic Acid & 0.03 & 0.02 & 0.04 & 0.02 & 0.11 & 0.11 \\
Syringaldehyde & - & - & - & - & 0.21 & 0.36 \\
Acetosyringone & - & - & - & - & 0.05 & 0.07 \\
\hline
\end{tabular}

a $\left(\bar{k}_{L, A}+\bar{k}_{O, A}\right) / \bar{k}_{A}^{\prime}$.

Through observations made during our study of lignin oxidative depolymerization and the model developed, a deeper understanding of the reaction mechanism was achieved (Figure 10). Based on the relation between the depolymerization rate and concentration of phenolic moieties uncovered by ${ }^{31} \mathrm{P} \mathrm{NMR}$, lignin oxidation appears to be initiated through the deprotonation of accessible phenolic moieties, in agreement with the work of Tarabanko et al. [58,59] Therefore, as more phenolic moieties are produced by lignin depolymerization, this crucial step could explain the need for a highly alkaline medium. 
Thereafter, two reaction pathways are triggered by the initiation of lignin oxidation, based on our kinetic model. The first and predominant route proceeds through degradation of the aromatic units by ring-opening reactions to generate small aliphatic molecules, such as oxalic acid or acetic acid. The second route probably consists of the cleavage of lignin's inter-unit linkages to produced lower $\mathrm{M}_{\mathrm{W}}$ compounds (oligomers, vanillin). Henceforth, these compounds can undergo condensation or ring-opening reactions. Noticeably, this route is deeply related to the concentration of lignin's inter-unit substructures as it has been illustrated during our study and other reports $[13,15,55]$. Ultimately, lignin oxidation leads to the formation of volatile compounds.

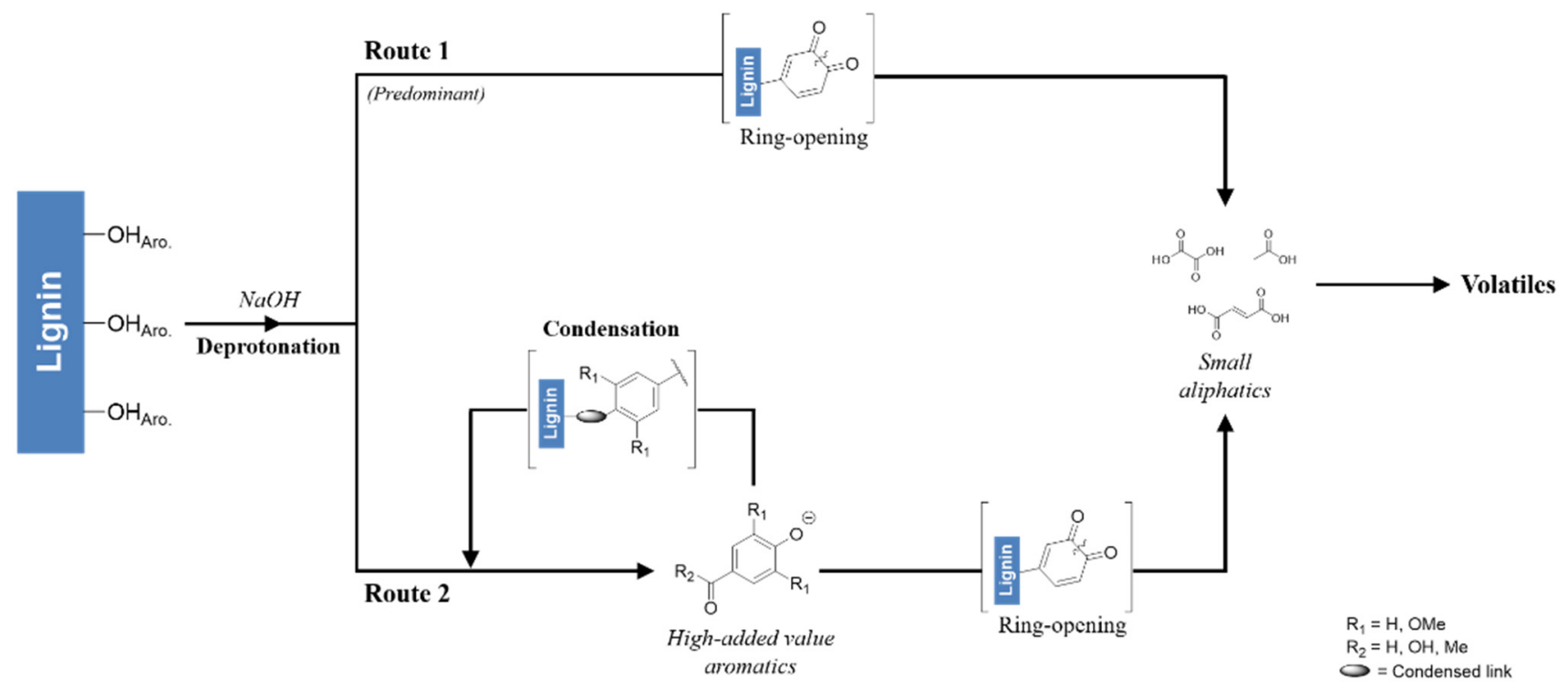

Figure 10. Schematic representation of lignin oxidative depolymerization's two pathways.

It is also noteworthy to mention that the development of the kinetic model allowed us to gain insights into the role of $\mathrm{Pt} / \mathrm{TiO}_{2}$. The catalyst proved to have a minimal effect on ring-opening reactions while promoting condensation reactions, thus shifting lignin oxidation towards the second route. Given the results presented in Figure 1, it can be assumed that $\mathrm{Au} / \mathrm{TiO}_{2}$, however, favored ring-opening reactions.

Furthermore, usage of the $\mathrm{Pt} / \mathrm{TiO}_{2}$ helped us recover from $3.4 \mathrm{wt} \%$ up to $7.7 \mathrm{wt} \%$ of aromatic aldehydes from Kraft, EOL-Ab and EOL-As lignins oxidation. Yields of vanillin/syringaldehyde ranging from 1 to $10 \mathrm{wt} \%$ for technical lignins have commonly been reported depending on the reaction conditions used (i.e., temperature, solvent, reaction time, oxidant, catalyst). While our results showed a great improvement, Schutyser et al. managed to obtain $\sim 15 \mathrm{wt} \%$ yields of aromatic aldehydes in similar conditions $\left(150{ }^{\circ} \mathrm{C}\right.$, 5 bar $\mathrm{O}_{2}, 30 \mathrm{~min}$ ) using native lignin with $\mathrm{CuSO}_{4}$ as a catalyst, thus further emphasizing the importance of lignin structure to optimize the production of lignin-derived aromatics [15].

Interestingly, Villar et al. and Schutyser et al. reported the use of a Pt/ $\mathrm{Al}_{2} \mathrm{O}_{3}$ to perform lignin oxidation and observed no improvement of the aromatic yields from the non-catalyzed reaction $[15,40]$, which contrast with our results. This might be explained by the relatively higher acidic properties of $\mathrm{Al}_{2} \mathrm{O}_{3}$, which has been reported in several studies $[51,52,60]$. Therefore, it appears that the effect of the support on lignin oxidation is an important feature to consider for the design of the catalysts as being wrong (e.g., $\mathrm{Al}_{2} \mathrm{O}_{3}$ ) as it seems to be able to shut down any catalytic effect. The design of a good heterogeneous catalyst is also evaluated by its ability to be recycled and reused. Therefore, both catalysts were analyzed after reaction by XRD analysis, and the amount of metal leached into the reaction media was also quantified. According to our results, XRD diffractograms (Figure S1) did not show any differences. However, $\mathrm{Pt} / \mathrm{TiO}_{2}$ displayed a ca. $18 \mathrm{wt} \%$ leaching of the metal. While this catalyst improved the yields of aromatics, further 
improvement will be necessary to obtain a recyclable catalyst and, thus, an economically viable process.

\section{Materials and Methods}

\subsection{General Information}

All chemicals were used as received from suppliers (Alfa Aesar (Kandel, Germany), Carl Roth (Karlsruhe, Germany), Merck Chemicals (Fontenay sous Bois, France) or SigmaAldrich (Saint Quentin Fallavier, France) and used without further purification.

\subsection{Lignin}

In this study, three different lignins were engaged: two softwood (Kraft and EOL$\mathrm{Ab}$ ) and one hardwood (EOL-As) lignin. Kraft lignin was produced from a black liquor (Pinus pinaster) from the paper industry, while EOL-Ab and EOL-As were extracted by Ethanol Organosolv process from abies and aspen woods respectively. The extraction procedure of these lignins as well as their characterizations, were previously reported [13].

\subsection{Catalysts}

A gold and a platinum supported over $\mathrm{TiO}_{2}$ were evaluated as catalyst. $\mathrm{Au} / \mathrm{TiO}_{2}$ $\left(1 \mathrm{wt} \% \mathrm{Au}, \mathrm{S}_{\mathrm{BET}} 40 \mathrm{~m}^{2} / \mathrm{g}\right.$ ) was purchased from Strem Chemicals. The platinum catalyst $\left(\mathrm{Pt} / \mathrm{TiO}_{2}\right.$ : $3.5 \mathrm{wt} \% \mathrm{Pt}, \mathrm{S}_{\mathrm{BET}} 90 \mathrm{~m}^{2} / \mathrm{g}$ ) was prepared by using a deposition-precipitation method in an aqueous solution of potassium tetrachloroplatinate using commercially available titania as support (DT51 $\mathrm{TiO}_{2}$, supplied by Millenium-now Cristal) [61]. $\mathrm{TiO}_{2}$ was slurried in water $(70 \mathrm{~mL})$, and a desired amount of $\mathrm{K}_{2} \mathrm{PtCl}_{4}$ solution was added. Then, the $\mathrm{pH}$ was set to 11 by addition of $\mathrm{KOH}$. The suspension was heated at $80^{\circ} \mathrm{C}$ for $1 \mathrm{~h}$ before being cooled and filtered. The recovered solid was washed with water, dried and reduced under hydrogen flow (flow rate: $60 \mathrm{~mL} / \mathrm{min}$; heating rate: $2{ }^{\circ} \mathrm{C} / \mathrm{min}$ up to $\mathrm{T}=300{ }^{\circ} \mathrm{C}$; $\mathrm{t}=3 \mathrm{~h}$ at $\mathrm{T}=300{ }^{\circ} \mathrm{C}$ ). Finally, after cooling and purging with Ar, the catalyst was passivated in $1 \% \mathrm{O}_{2} / \mathrm{N}_{2}$.

Both catalyst's characterization can be found in Table S1 and Figure S1.

\subsection{Analytical Methods}

The analytical methods were previously described [13].

NMR analyses were performed with a Bruker AVANCE III 400MHz spectrometer equipped with a BBFO probe ( $Z$ gradient) (Bruker Corporation, Billerica, MA, USA). HSQC NMR analyses, the acquisitions were realized at $50{ }^{\circ} \mathrm{C}$ (hsqcedetgpsp.3; 48 scans). Lignin samples (c.a. $50 \mathrm{mg}$ ) were dissolved in $600 \mathrm{mg}$ of DMSO-d ${ }^{6}$. The characterization and quantification of hydroxyl groups in lignin were made using previously developed methods [62,63]. For this analysis, 2-chloro-4,4,5,5-tetramethyl-1,3,2-dioxaphospholane (TMDP) is used as a phosphytilation agent to quantify the different $\mathrm{OH}$ groups (phenol, aliphatic, carboxylic). Samples were accurately weighted (c.a. $30 \mathrm{mg}$ ) and solubilized in $0.5 \mathrm{~mL}$ of a solution of cyclohexanol $\left(3.95 \mathrm{mg} / \mathrm{g}_{\text {solution }}\right.$-internal standard $)$ in pyridine and $\mathrm{DMF}$ (v/v: 1/1). Once dissolved, $200 \mathrm{mg}$ of $\mathrm{CDCl}_{3}$ were added before introducing $100 \mathrm{mg}$ of TMDP. The product of the reaction of TMDP with water $(\delta=132.2 \mathrm{ppm})$ was used to calibrate the chemical shifts.

GC-MS analyses were carried out with a Shimadzu GC-MS-QP2010S equipped with an AOC-20i+ autosampler (Shimadzu Europa GmbH, Duisburg, Nordrhein-Westfalen, DE) and a Sulpelco SLB-5MS column (5\% Phenyl-95\% dimethylpolysiloxane, $30 \mathrm{~m} \times$ $0.25 \mathrm{~mm} \times 0.25 \mu \mathrm{m})$. Helium was used as carrier gas with the following program: $60^{\circ} \mathrm{C}$ for $2 \mathrm{~min} /$ Heat up to $150{ }^{\circ} \mathrm{C}$ (rate $30^{\circ} \mathrm{C} / \mathrm{min}$ ) / Heat up to $200{ }^{\circ} \mathrm{C}$ (rate $2{ }^{\circ} \mathrm{C} / \mathrm{min}$ )/Heat up to $300{ }^{\circ} \mathrm{C}$ (rate $10{ }^{\circ} \mathrm{C} / \mathrm{min}$ ) $/ 300{ }^{\circ} \mathrm{C}$ for $2 \mathrm{~min}$ ).

\subsection{Lignin Oxidative Depolymerization}

Lignin oxidation was performed by a procedure described in the literature with some modifications [13]. In a $300 \mathrm{~mL}$ batch reactor equipped with $260 \mathrm{~mL}$ air ballast $\left(20 \% \mathrm{O}_{2}\right.$, 
$\left.80 \% \mathrm{~N}_{2}\right), 150 \mathrm{~mL}$ of a solution of lignin $\left(\mathrm{C}_{\text {Lignin }}: 5 \mathrm{~g} / \mathrm{L}\right)$ and $\mathrm{NaOH}$ was inserted with the catalyst (ratio $\mathrm{m}_{\text {metal }} / \mathrm{m}_{\text {Lignin }}=0.1 \mathrm{wt} \%$ ) before closing the reactor. In order to obtain an inert atmosphere, the reactor was pressurized and depressurized 3 times with Ar. Then, the system was heated to the desired temperature $\left(150{ }^{\circ} \mathrm{C}\right)$ under $1500 \mathrm{rpm}$. Once the targeted temperature was attained, the reactor was pressurized with air, thus marking the depolymerization starting point. Pressure transmitters (Keller PR33 with a converter Keller K-104) allowed the recording of the pressure in the reactor as well as the oxygen consumption in the ballast. The depolymerization was stopped after a targeted amount of time by using an ice bath.

Thereafter, the recovered reaction mixture was filtered to remove the catalyst before the fractionation process (Figure 11). The filtrate was acidified by a $10 \%$ solution of $\mathrm{HCl}$ to reach a $\mathrm{pH}$ of 1 and precipitate appeared. The solid was separated by centrifugation for $10 \mathrm{~min}$ at $4000 \mathrm{rpm}$ and washed twice with a $10 \%$ solution of $\mathrm{HCl}$, thus leading to the recovery of the so-called "precipitate" fraction after drying. Then, DCM $(100 \mathrm{~mL} \times 3)$ was used to extract the aromatics from the supernatant ("DCM" fraction). The remaining aqueous phase was dried in vacuo. Finally, THF was poured onto the resulting residue, leading to the solubilization of lignin adducts ("THF" fraction) and the removal of salts by subsequent centrifugation. The analysis of each fraction showed three structurally distinct structures, i.e., a highly modified biopolymer ("Precipitate"), a low molecular weight aliphatic fraction ("THF" fraction) and a high added-value aromatic fraction ("DCM" fraction).

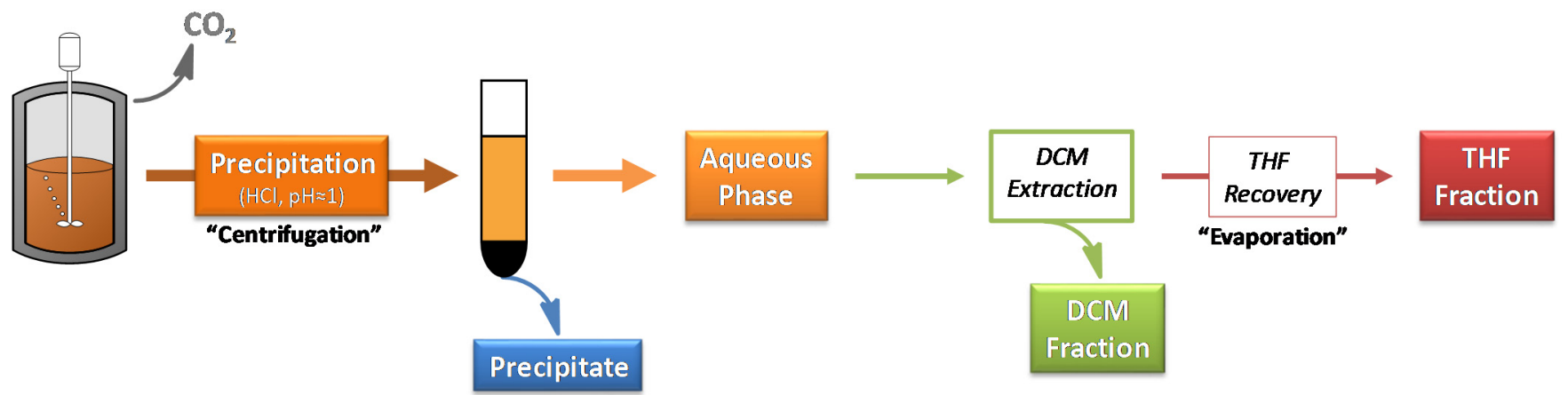

Figure 11. Schematic representation of fractionation protocol used for treating the reaction mixture after lignin oxidation.

The yields of the fraction recovered and aromatic yields were expressed as a function of the mass of lignin engaged:

$$
\text { Yield }(\mathrm{w} t \%)=100 \times \frac{m_{\text {recovered }}}{m_{\text {Lignin engaged }}}
$$

Even though the "precipitate" is functionally and structurally different from the starting material (see below), lignin conversion was arbitrarily defined as follows:

$$
\text { Conversion }(\%)=100-y_{\text {Precipitate }}
$$

\section{Conclusions}

In this contribution, supported metals catalysts were evaluated for the production of high added-value aromatic compounds from three lignins (Kraft, EOL-Ab, EOL-As) by oxidative depolymerization under basic conditions. Two metal-based catalysts were considered, and they demonstrated that they mainly react with the primary products of lignin oxidative depolymerization. $\mathrm{Au} / \mathrm{TiO}_{2}$ showed a strong propensity to degrade aromatic moieties and, thus was not further studied. On the other hand, $\mathrm{Pt} / \mathrm{TiO}_{2}$ displayed an increase of aromatic yields, mainly vanillin and syringaldehyde.

Therefore, this catalyst was considered to perform kinetic studies under the selected reaction conditions $\left(\mathrm{T}: 150^{\circ} \mathrm{C}, \mathrm{P}_{\text {air }}: 20\right.$ bar, $\left.\mathrm{C}_{\mathrm{NaOH}}: 10 \mathrm{~g} / \mathrm{L}\right)$. Due to lignin oxidation's high 
level of complexity, the fractionation protocol previously developed allowed us to analyze lignin adducts as a whole, contrary to the approach usually reported, which investigates only the targeted compounds. Interestingly, $\mathrm{Pt} / \mathrm{TiO}_{2}$ demonstrated an ability to preserve lignin's sub-structures resulting in an increase of aromatic yields and a decrease of aliphatic compounds. Therefore, a kinetic model was constructed as a mean to understand the role of the catalyst during lignin oxidation. Through the development of this model, the authors identified the occurrence of condensation reactions during lignin oxidation and demonstrated that $\mathrm{Pt} / \mathrm{TiO}_{2}$ was capable of guiding the reaction towards the formation of the targeted compounds through enhancement of these condensation reactions.

Although catalysis improved the recovery of the targeted compounds, degradation of the aromatic rings remains the major pathway for lignin oxidative depolymerization. However, the development of a kinetic model enabled us to gain insights into lignin oxidation and the catalyst's role. Consequently, a better understanding could pave the way to a better control of lignin oxidative depolymerization by designing catalysts according to the targeted compounds whether it is small aromatic compounds or aliphatic carboxylic acid.

Supplementary Materials: The following are available online at https: / www.mdpi.com/article/ 10.3390/catal11040467/s1, Table S1: Percentage of metal on each catalyst and BET surface area determination; Figure S1: XRD Diffractograms of $\mathrm{Au} / \mathrm{TiO}_{2}$ and $\mathrm{Pt} / \mathrm{TiO}_{2}$; Figure S2: Evolution of vanillin, syringaldehyde and acetovanillone degradation; Figure S3: Influence of air pressure on Kraft lignin conversion and yields of the main aromatic compounds; Figure S4: HSQC NMR structural identification; Figure S5: HSQC NMR spectra of Kraft, EOL-Ab and EOL-As lignins; Figures S6-S8: HSQC NMR spectra of the "precipitate" obtained after Kraft, EOL-Ab and EOL-As lignins oxidation; Figure S9: Semi-quantitative analyses of the ratio of inter-unit bonds in Kraft, EOL-Ab and EOL-As lignins; Figure S10: Representation of EOL-As lignin oxidative depolymerization predicted by model a and model b; Figures S11-S12: Evolution of the three fractions and the yields of aromatics during catalyzed and non-catalyzed lignin oxidation for Kraft, EOL-Ab and EOL-As lignins.

Author Contributions: The manuscript was written through contributions of all authors. All authors have read and agreed to the published version of the manuscript.

Funding: This research was funded by the National Agency of Research (CHEMLIVAL $\mathrm{N}^{\circ}$ ANR-12CDII-0001_01).

Data Availability Statement: The data presented in this study are available on request from the corresponding author.

Acknowledgments: The authors thank C. Lorentz for her help with the NMR analyses. The authors gratefully acknowledge the National Agency of Research (CHEMLIVAL N ${ }^{\circ}$ ANR-12-CDII-0001_01) for funding. C.C.A. thanks the National Agency of Research (CHEMLIVAL N ${ }^{\circ}$ ANR-12-CDII-0001_01) for grant. A. K. thanks GDRI (International Research Network) "Catalytic upgrading of Biomass" for grant. The authors thank AXELERA, cluster for the chemical and environmental sectors, for support.

Conflicts of Interest: The authors declare no conflict of interest.

\section{References}

1. Lange, H.; Decina, S.; Crestini, C. Oxidative upgrade of lignin-Recent routes reviewed. Eur. Polym. J. 2013, 49, 1151-1173. [CrossRef]

2. Schutyser, W.; Renders, T.; Van den Bosch, S.; Koelewijn, S.F.; Beckham, G.T.; Sels, B.F. Chemicals from lignin: An interplay of lignocellulose fractionation, depolymerisation, and upgrading. Chem. Soc. Rev. 2018, 47, 852-908. [CrossRef] [PubMed]

3. Ma, R.; Guo, M.; Zhang, X. Recent advances in oxidative valorization of lignin. Catal. Today 2018, 302, 50-60. [CrossRef]

4. Liu, X.; Bouxin, F.P.; Fan, J.; Budarin, V.L.; Hu, C.; Clark, J.H. Recent Advances in the Catalytic Depolymerization of Lignin towards Phenolic Chemicals: A Review. ChemSusChem 2020, 13, 4296-4317. [CrossRef] [PubMed]

5. Becker, J.; Wittmann, C. A field of dreams: Lignin valorization into chemicals, materials, fuels, and health-care products. Biotechnol. Adv. 2019, 37, 107360. [CrossRef] [PubMed]

6. Joffres, B.; Laurenti, D.; Charon, N.; Daudin, A.; Quignard, A.; Geantet, C. Thermochemical Conversion of Lignin for Fuels and Chemicals: A Review. Oil Gas Sci. Technol.-Rev. IFP Energies Nouv. 2013, 68, 753-763. [CrossRef]

7. Chatel, G.; Rogers, R.D. Review: Oxidation of Lignin Using Ionic Liquids-An Innovative Strategy to Produce Renewable Chemicals. ACS Sus. Chem. Eng. 2014, 2, 322-339. [CrossRef] 
8. Ha, J.-M.; Hwang, K.-R.; Kim, Y.-M.; Jae, J.; Kim, K.H.; Lee, H.W.; Kim, J.-Y.; Park, Y.-K. Recent progress in the thermal and catalytic conversion of lignin. Renew. Sustain. Energy Rev. 2019, 111, 422-441. [CrossRef]

9. Chio, C.; Sain, M.; Qin, W. Lignin utilization: A review of lignin depolymerization from various aspects. Renew. Sustain. Energy Rev. 2019, 107, 232-249. [CrossRef]

10. Wang, H.; Pu, Y.; Ragauskas, A.; Yang, B. From lignin to valuable products-strategies, challenges, and prospects. Bioresour. Technol. 2019, 271, 449-461. [CrossRef] [PubMed]

11. Deuss, P.J.; Barta, K. From models to lignin: Transition metal catalysis for selective bond cleavage reactions. Coord. Chem. Rev. 2016, 306, 510-532. [CrossRef]

12. Hanson, S.K.; Baker, R.T. Knocking on Wood: Base Metal Complexes as Catalysts for Selective Oxidation of Lignin Models and Extracts. Acc. Chem. Res. 2015, 48, 2037-2048. [CrossRef]

13. Almada, C.C.; Kazachenko, A.; Fongarland, P.; Da Silva Perez, D.; Kuznetsov, B.N.; Djakovitch, L. Oxidative depolymerization of lignins for producing aromatics: Variation of botanical origin and extraction methods. Biomass Convers. Biorefinery 2020. [CrossRef]

14. Rinaldi, R.; Jastrzebski, R.; Clough, M.T.; Ralph, J.; Kennema, M.; Bruijnincx, P.C.A.; Weckhuysen, B.M. Paving the Way for Lignin Valorisation: Recent Advances in Bioengineering, Biorefining and Catalysis. Angew. Chem. Int. Ed. 2016, 55, 8164-8215. [CrossRef]

15. Schutyser, W.; Kruger, J.S.; Robinson, A.M.; Katahira, R.; Brandner, D.G.; Cleveland, N.S.; Mittal, A.; Peterson, D.J.; Meilan, R.; Román-Leshkov, Y.; et al. Revisiting alkaline aerobic lignin oxidation. Green Chem. 2018, 20, 3828-3844. [CrossRef]

16. Crestini, C.; Pro, P.; Neri, V.; Saladino, R. Methyltrioxorhenium: A new catalyst for the activation of hydrogen peroxide to the oxidation of lignin and lignin model compounds. Bioorganic Med. Chem. 2005, 13, 2569-2578. [CrossRef] [PubMed]

17. Chakar, F.S.; Ragauskas, A.J. Review of current and future softwood kraft lignin process chemistry. Ind. Crops Prod. 2004, 20, 131-141. [CrossRef]

18. Abejón, R.; Pérez-Acebo, H.; Clavijo, L. Alternatives for Chemical and Biochemical Lignin Valorization: Hot Topics from a Bibliometric Analysis of the Research Published During the 2000-2016 Period. Processes 2018, 6, 98. [CrossRef]

19. Zucca, P.; Rescigno, A.; Rinaldi, A.C.; Sanjust, E. Biomimetic metalloporphines and metalloporphyrins as potential tools for delignification: Molecular mechanisms and application perspectives. J. Mol. Catal. A Chem. 2014, 388-389, 2-34. [CrossRef]

20. Gasser, C.A.; Hommes, G.; Schäffer, A.; Corvini, P.F.X. Multi-catalysis reactions: New prospects and challenges of biotechnology to valorize lignin. Appl. Microbiol. Biotechnol. 2012, 95, 1115-1134. [CrossRef]

21. Crestini, C.; Saladino, R.; Tagliatesta, P.; Boschi, T. Biomimetic degradation of lignin and lignin model compounds by synthetic anionic and cationic water soluble manganese and iron porphyrins. Bioorganic Med. Chem. 1999, 7, 1897-1905. [CrossRef]

22. Crestini, C.; Pastorini, A.; Tagliatesta, P. Metalloporphyrins immobilized on motmorillonite as biomimetic catalysts in the oxidation of lignin model compounds. J. Mol. Catal. A Chem. 2004, 208, 195-202. [CrossRef]

23. Zhu, C.; Ding, W.; Shen, T.; Tang, C.; Sun, C.; Xu, S.; Chen, Y.; Wu, J.; Ying, H. Metallo-Deuteroporphyrin as a Biomimetic Catalyst for the Catalytic Oxidation of Lignin to Aromatics. ChemSusChem 2015, 8, 1768-1778. [CrossRef]

24. Harms, R.G.; Markovits, I.I.E.; Drees, M.; Herrmann, H.M.; Cokoja, M.; Kühn, F.E. Cleavage of C-O Bonds in Lignin Model Compounds Catalyzed by Methyldioxorhenium in Homogeneous Phase. ChemSusChem 2014, 7, 429-434. [CrossRef]

25. Voitl, T.; Rudolf von Rohr, P. Oxidation of Lignin Using Aqueous Polyoxometalates in the Presence of Alcohols. ChemSusChem 2008, 1, 763-769. [CrossRef] [PubMed]

26. Rawat, S.; Gupta, P.; Singh, B.; Bhaskar, T.; Natte, K.; Narani, A. Molybdenum-catalyzed oxidative depolymerization of alkali lignin: Selective production of Vanillin. Appl. Catal. A Gen. 2020, 598, 117567. [CrossRef]

27. Zhou, X.-F.; Lu, X.-J. Co(salen) supported on graphene oxide for oxidation of lignin. J. Appl. Polym. Sci. 2016, 133. [CrossRef]

28. Walch, F.; Abdelaziz, O.Y.; Meier, S.; Bjelić, S.; Hulteberg, C.P.; Riisager, A. Oxidative depolymerization of Kraft lignin to high-value aromatics using a homogeneous vanadium-copper catalyst. Catal. Sci. Technol. 2021, 11, 1843-1853. [CrossRef]

29. Bjørsvik, H.-R.; Minisci, F. Fine Chemicals from Lignosulfonates. 1. Synthesis of Vanillin by Oxidation of Lignosulfonates. Org. Proc. Res. Dev. 1999, 3, 330-340. [CrossRef]

30. Crestini, C.; Caponi, M.C.; Argyropoulos, D.S.; Saladino, R. Immobilized methyltrioxo rhenium (MTO)/ $\mathrm{H}_{2} \mathrm{O}_{2}$ systems for the oxidation of lignin and lignin model compounds. Bioorganic Med. Chem. 2006, 14, 5292-5302. [CrossRef]

31. Crestini, C.; Pastorini, A.; Tagliatesta, P. The Immobilized Porphyrin-Mediator System Mn(TMePyP)/clay/HBT (clay-PMS): A Lignin Peroxidase Biomimetic Catalyst in the Oxidation of Lignin and Lignin Model Compounds. Eur. J. Inorg. Chem. 2004, 2004, 4477-4483. [CrossRef]

32. Kumar, A.; Jain, N.; Chauhan, S.M.S. Biomimetic Oxidation of Veratryl Alcohol with $\mathrm{H}_{2} \mathrm{O}_{2}$ Catalyzed by Iron(III) Porphyrins and Horseradish Peroxidase in Ionic Liquid. Synlett 2007, 2007, 0411-0414. [CrossRef]

33. Zhao, L.; Shi, S.; Liu, M.; Zhu, G.; Wang, M.; Du, W.; Gao, J.; Xu, J. Covalent triazine framework catalytic oxidative cleavage of lignin models and organosolv lignin. Green Chem. 2018, 20, 1270-1279. [CrossRef]

34. Lancefield, C.S.; Ojo, O.S.; Tran, F.; Westwood, N.J. Isolation of Functionalized Phenolic Monomers through Selective Oxidation and C-O Bond Cleavage of the $\beta-\mathrm{O}-4$ Linkages in Lignin. Angew. Chem. Int. Ed. 2015, 54, 258-262. [CrossRef] [PubMed]

35. Deng, H.; Lin, L.; Sun, Y.; Pang, C.; Zhuang, J.; Ouyang, P.; Li, Z.; Liu, S. Perovskite-type Oxide LaMnO L $_{3}$ An Efficient and Recyclable Heterogeneous Catalyst for the Wet Aerobic Oxidation of Lignin to Aromatic Aldehydes. Catal. Lett. 2008, 126, 106. [CrossRef]

36. Deng, H.; Lin, L.; Liu, S. Catalysis of Cu-Doped Co-Based Perovskite-Type Oxide in Wet Oxidation of Lignin To Produce Aromatic Aldehydes. Energy Fuels 2010, 24, 4797-4802. [CrossRef] 
37. Deng, H.; Lin, L.; Sun, Y.; Pang, C.; Zhuang, J.; Ouyang, P.; Li, J.; Liu, S. Activity and Stability of Perovskite-Type Oxide LaCoO 3 Catalyst in Lignin Catalytic Wet Oxidation to Aromatic Aldehydes Process. Energy Fuels 2009, 23, 19-24. [CrossRef]

38. Yang, M.; Xu, A.; Du, H.; Sun, C.; Li, C. Removal of salicylic acid on perovskite-type oxide $\mathrm{LaFeO}_{3}$ catalyst in catalytic wet air oxidation process. J. Hazard. Mater. 2007, 139, 86-92. [CrossRef] [PubMed]

39. Royer, S.; Levasseur, B.; Alamdari, H.; Barbier, J.; Duprez, D.; Kaliaguine, S. Mechanism of stearic acid oxidation over nanocrystalline $\mathrm{La}_{1-\mathrm{x}} \mathrm{A}^{\prime}{ }_{\mathrm{x}} \mathrm{BO}_{3}\left(\mathrm{~A}^{\prime}=\mathrm{Sr}, \mathrm{Ce} ; \mathrm{B}=\mathrm{Co}, \mathrm{Mn}\right)$ : The role of oxygen mobility. Appl. Catal. B Environ. 2008, 80, 51-61. [CrossRef]

40. Villar, J.C.; Caperos, A.; García-Ochoa, F. Oxidation of hardwood kraft-lignin to phenolic derivatives with oxygen as oxidant. Wood Sci.Technol. 2001, 35, 245-255. [CrossRef]

41. Crestini, C.; Crucianelli, M.; Orlandi, M.; Saladino, R. Oxidative strategies in lignin chemistry: A new environmental friendly approach for the functionalisation of lignin and lignocellulosic fibers. Catal. Today 2010, 156, 8-22. [CrossRef]

42. Luo, J.; Melissa, P.; Zhao, W.; Wang, Z.; Zhu, Y. Selective Lignin Oxidation towards Vanillin in Phenol Media. ChemistrySelect 2016, 1, 4596-4601. [CrossRef]

43. Pearl, I.A.; Beyer, D.L. Oxidation of Alkali Lignin. In Lignin Structure and Reactions; American Chemical Society: Washington, DC, USA, 1966; Volume 59, pp. 145-156.

44. Kumar, A.; Biswas, B.; Saini, K.; Kumar, A.; Kumar, J.; Krishna, B.B.; Bhaskar, T. Copper and manganese bimetallic catalysts for oxidation of prot lignin: Effects of metal oxide on product yield. Biomass Convers. Biorefinery 2021. [CrossRef]

45. Hdidou, L.; Khallouk, K.; Solhy, A.; Manoun, B.; Oukarroum, A.; Barakat, A. Synthesis of CoFeO mixed oxides via an alginate gelation process as efficient heterogeneous catalysts for lignin depolymerization in water. Catal. Sci. Technol. 2018, 8 , 5445-5453. [CrossRef]

46. Sun, K.; Chen, S.; Zhang, J.; Lu, G.-P.; Cai, C. Cobalt Nanoparticles Embedded in N-Doped Porous Carbon Derived from Bimetallic Zeolitic Imidazolate Frameworks for One-Pot Selective Oxidative Depolymerization of Lignin. ChemCatChem 2019, 11, 1264-1271. [CrossRef]

47. Song, Y.; Mobley, J.K.; Motagamwala, A.H.; Isaacs, M.; Dumesic, J.A.; Ralph, J.; Lee, A.F.; Wilson, K.; Crocker, M. Gold-catalyzed conversion of lignin to low molecular weight aromatics. Chem. Sci. 2018, 9, 8127-8133. [CrossRef] [PubMed]

48. Deng, W.; Zhang, H.; Wu, X.; Li, R.; Zhang, Q.; Wang, Y. Oxidative conversion of lignin and lignin model compounds catalyzed by $\mathrm{CeO}_{2}$-supported Pd nanoparticles. Green Chem. 2015, 17, 5009-5018. [CrossRef]

49. Kuznetsov, B.N.; Sharypov, V.I.; Baryshnikov, S.V.; Miroshnikova, A.V.; Taran, O.P.; Yakovlev, V.A.; Lavrenov, A.V.; Djakovitch, L. Catalytic hydrogenolysis of native and organosolv lignins of aspen wood to liquid products in supercritical ethanol medium. Catal. Today 2020. [CrossRef]

50. Sales, F.G.; Maranhão, L.C.A.; Lima Filho, N.M.; Abreu, C.A.M. Kinetic Evaluation and Modeling of Lignin Catalytic Wet Oxidation to Selective Production of Aromatic Aldehydes. Ind. Eng. Chem. Res. 2006, 45, 6627-6631. [CrossRef]

51. Bjelić, A.; Grilc, M.; Huš, M.; Likozar, B. Hydrogenation and hydrodeoxygenation of aromatic lignin monomers over Cu/C, $\mathrm{Ni} / \mathrm{C}, \mathrm{Pd} / \mathrm{C}, \mathrm{Pt} / \mathrm{C}, \mathrm{Rh} / \mathrm{C}$ and $\mathrm{Ru} / \mathrm{C}$ catalysts: Mechanisms, reaction micro-kinetic modelling and quantitative structure-activity relationships. Chem. Eng. J. 2019, 359, 305-320. [CrossRef]

52. Bjelić, A.; Grilc, M.; Likozar, B. Bifunctional metallic-acidic mechanisms of hydrodeoxygenation of eugenol as lignin model compound over supported $\mathrm{Cu}, \mathrm{Ni}, \mathrm{Pd}, \mathrm{Pt}$, Rh and Ru catalyst materials. Chem. Eng. J. 2020, 394, 124914. [CrossRef]

53. Figueirêdo, M.B.; Venderbosch, R.H.; Deuss, P.J.; Heeres, H.J. A Two-Step Approach for the Conversion of Technical Lignins to Biofuels. Adv. Sustain. Syst. 2020, 4, 1900147. [CrossRef]

54. Ma, R.; Guo, M.; Zhang, X. Selective Conversion of Biorefinery Lignin into Dicarboxylic Acids. ChemSusChem 2014, 7, 412-415. [CrossRef]

55. Wang, Y.; Sun, S.; Li, F.; Cao, X.; Sun, R. Production of vanillin from lignin: The relationship between $\beta$-O-4 linkages and vanillin yield. Ind. Crops Prod. 2018, 116, 116-121. [CrossRef]

56. Zhu, Y.; Liu, J.; Liao, Y.; Lv, W.; Ma, L.; Wang, C. Degradation of Vanillin During Lignin Valorization Under Alkaline Oxidation. Top. Curr. Chem. 2018, 376, 29. [CrossRef]

57. Casimiro, F.M.; Costa, C.A.E.; Botelho, C.M.; Barreiro, M.F.; Rodrigues, A.E. Kinetics of Oxidative Degradation of Lignin-Based Phenolic Compounds in Batch Reactor. Ind. Eng. Chem. Res. 2019, 58, 16442-16449. [CrossRef]

58. Tarabanko, V.E.; Petukhov, D.V.; Selyutin, G.E. New Mechanism for the Catalytic Oxidation of Lignin to Vanillin. Kinet. Catal. 2004, 45, 569-577. [CrossRef]

59. Tarabanko, V.E.; Fomova, N.A.; Kuznetsov, B.N.; Ivanchenko, N.M.; Kudryashev, A.V. On the mechanism of vanillin formation in the catalytic oxidation of lignin with oxygen. React. Kinet. Catal. Lett. 1995, 55, 161-170. [CrossRef]

60. Hita, I.; Deuss, P.J.; Bonura, G.; Frusteri, F.; Heeres, H.J. Biobased chemicals from the catalytic depolymerization of Kraft lignin using supported noble metal-based catalysts. Fuel Process. Technol. 2018, 179, 143-153. [CrossRef]

61. Ait Rass, H.; Essayem, N.; Besson, M. Selective Aerobic Oxidation of 5-HMF into 2,5-Furandicarboxylic Acid with Pt Catalysts Supported on $\mathrm{TiO}_{2}$ - and $\mathrm{ZrO}_{2}$-Based Supports. ChemSusChem 2015, 8, 1206-1217. [CrossRef]

62. Granata, A.; Argyropoulos, D.S. 2-Chloro-4,4,5,5-tetramethyl-1,3,2-dioxaphospholane, a Reagent for the Accurate Determination of the Uncondensed and Condensed Phenolic Moieties in Lignins. J. Agric. Food. Chem. 1995, 43, 1538-1544. [CrossRef]

63. Popescu, C.-M.; Popescu, M.-C.; Singurel, G.; Vasile, C.; Argyropoulos, D.S.; Willfor, S. Spectral Characterization of Eucalyptus Wood. Appl. Spectrosc. 2007, 61, 1168-1177. [CrossRef] [PubMed] 